\title{
Moisture-Conductivity Calibration for Electrical Imaging of Horticultural Substrate
}

\author{
Peng-Fei Zhao ${ }^{1,2} \mathbb{D}$, Li-Feng Fan ${ }^{1,3}$, Yong-Qian Wang ${ }^{4}$, Yang Li $^{1,3}$, Nan Wang ${ }^{1,2}$, Zhong-Yi Wang ${ }^{1,2,3} \mathbb{D}^{\text {, }}$ \\ Qiang Cheng ${ }^{1, *}$ and Lan Huang ${ }^{2, *(\mathbb{D}}$
}

1 College of Information and Electrical Engineering, China Agricultural University, Beijing 100083, China; zgndndzpf@cau.edu.cn (P.-F.Z.); zgndnd-flfwxj@cau.edu.cn (L.-F.F.); Cauliyang@126.com (Y.L.); b20193080652@cau.edu.cn (N.W.); wzyhl@cau.edu.cn (Z.-Y.W.)

2 Key Laboratory of Agricultural Information Acquisition Technology (Beijing), Ministry of Agriculture, Beijing 100083, China

3 Key Laboratory of Modern Precision Agriculture System Integration Research, Ministry of Education, Beijing 100083, China

4 School of Instrument Science and Opto Electronic Engineering, Beijing Information Science and Technology University, Beijing 100192, China; wangyongqian@bistu.edu.cn

* $\quad$ Correspondence: chengqiang@cau.edu.cn (Q.C.); hlan@cau.edu.cn (L.H.); Tel.: +86-10-62737778 (L.H.)

Citation: Zhao, P.-F.; Fan, L.-F.; Wang, Y.-Q.; Li, Y.; Wang, N.; Wang, Z.-Y.; Cheng, Q.; Huang, L. Moisture-Conductivity Calibration for Electrical Imaging of Horticultural Substrate. Agriculture 2021, 11, 899. https://doi.org/10.3390/ agriculture11090899

Academic Editor: Nándor Fodor

Received: 15 August 2021

Accepted: 16 September 2021

Published: 18 September 2021

Publisher's Note: MDPI stays neutral with regard to jurisdictional claims in published maps and institutional affiliations.

Copyright: (c) 2021 by the authors. Licensee MDPI, Basel, Switzerland. This article is an open access article distributed under the terms and conditions of the Creative Commons Attribution (CC BY) license (https:// creativecommons.org/licenses/by/ $4.0 /)$.

\begin{abstract}
Electrical imaging studies of laboratory- and small-scale plant root zones are gaining increasing attention. However, for essential moisture-conductivity calibrations on numerous substrate columns with variability in dry density, the use of one conventional strategy is relatively laborious or complicated. Thus, in this work, a relatively convenient calibration method is presented, and the objective is to identify its feasibility and potential to assess the effects of factors (e.g., volumetric water content (VWC), and dry density) on conductivity and establish necessary moisture-conductivity curves for porous materials (e.g., soils and substrates). In the method, with a specially designed fixture, variable VWCs, dry densities and related complex conductivities of the samples can be easily acquired through static compaction. The results show that the in-phase conductivity (or magnitude of conductivity) increases with the increasing VWC or dry density, primarily owing to the increase in the dominant pore water connectivity. Moreover, the effect of dry density on conductivity is relatively smaller than that of VWC. Thus, for the substrates at dry densities with certain variability, good power law relations ( $R^{2} \geq 0.99$ ) between in-phase conductivity (or magnitude of conductivity) and VWC at different frequencies can be established. Overall, the proposed approach is practical, promising, and relatively time- and labor-saving.
\end{abstract}

Keywords: horticultural substrate; complex conductivity; frequency; moisture; density; calibration

\section{Introduction}

Soil conductivity can be used to estimate the physical, chemical and biological properties of interest (e.g., moisture, texture, and salinity), and its measurement and monitoring play a significant role for numerous application fields, particularly for soil, water and fertilizer management in agriculture [1,2]. Compared with traditional point- and sample-scale measurement techniques, electrical imaging (e.g., electrical resistivity tomography (ERT) and electrical impedance tomography (EIT)) can map the spatially distributed electrical properties (e.g., conductivities) in an observed domain. Moreover, due to its advantages, such as the suitability for portable and cost-effective instrument implementation, the applicability at various spatiotemporal scales and the capability of functional characterization in addition to structural mapping, electrical imaging has been a very attractive approach for monitoring soil zones (or related plant root zones) in recent years; an increasing number of related studies to measure roots or root zone processes have been performed. However, in order to quantitatively monitor the moisture dynamics or water-related processes in a root 
zone, an additional related calibration to correlate the electrical parameter (e.g., conductivity) to the expected soil property (e.g., moisture and salinity) is indispensably required.

To establish the necessary calibration relations (usually moisture-conductivity curves) for the specific underground media (e.g., soil and substrate) and under the particular circumstances, there exist different calibration strategies [1,2]. In a given ex situ laboratory calibration, soil samples obtained from the field are controlled to different volumetric water contents (VWCs), and then they are individually repacked into a specific test box to measure their bulk conductivities [3-5]. However, in the above laboratory calibration, samples are disturbed, and the effect of pore structure (or tortuosity) is ignored [2]. In another kind of laboratory calibration, undisturbed soil samples are loaded into specially designed cylindrical test cells so that the sample saturation and desaturation, using an air injection device as well as the related conductivity measurements, are allowed [6-8], and thus, the samples' natural pore structures can be kept. In an in situ field calibration, the soil conductivity measurements at a particular position are conducted, and the related VWC measurements using sensors, such as time-domain reflectometry probes, are performed simultaneously. In general, a laboratory or field calibration is required to establish a specific relationship for each individual site, and a field calibration is more practical than a laboratory one [1,2,9]. Moreover, in an effort to remove the requirement for site-specific calibrations, a field-based pedotransfer function was developed [10]. The function performed moderately well, and although further examination of its validity on other expected soils and the developments of other functions for other types of soils are required, the methodology has the potential to reduce the efforts for calibrations and thus, is promising [1,2]. Furthermore, it is usually necessary to perform laboratory or field calibrations at different horizontal locations and depths for soils with significant heterogeneity. Factors such as changes in the pore water conductivity and the presence of roots could affect the calibration relation [1].

In most related studies of root zones, ERT (generally at a frequency of less than $1 \mathrm{kHz}$ ) is widely applied, and calibrations between direct current (DC) (or low frequency) conductivity and moisture are performed, while in those using EIT (usually at a higher frequency), links between alternating current (AC) (or complex) conductivity and moisture are required $[1,2,11]$. At present, there are some published works focusing on the complex conductivity (or spectral induced polarization (SIP)) measurements of soils in the frequency range below several tens of $\mathrm{kHz}$. In these studies, the effect of the water saturation, which can be related to the VWC through the porosity, on the complex conductivity were investigated, and it was shown that the magnitude of complex conductivity, the in-phase conductivity, and even the quadrature conductivity follow power-law relations with the saturation [11-15]. Additionally, in some other works focusing on soil moisture measurements, the related electrical measurements were performed in wider frequency ranges of up to several MHz, and despite the presence of the effects of electrode polarization, the related results show good regular relations at different frequencies between the measured resistivity (or impedance, conductivity) and the water content [16-18]. In addition to the VWC, the dry density related to the porosity also has an effect on the soil conductivity; there are also some studies focusing on the effects of factors such as moisture and density on DC conductivity (or resistivity) of soils, where static compaction was used to control the density of the related samples $[19,20]$.

In recent years, with the polarization features of root zones gaining increasing attention, methods such as EIT have been applied in a few small-scale studies [1,21-23]. In soilless cultivations in greenhouses, horticultural substrates are commonly used because of their benefits, such as good structure and water-holding capacity, strong controllability, lack of disease and saline-alkali conditions [16,24]; substrates can be used for studies of dynamics in laboratory- and small-scale root zones, using electrical imaging, and can allow better focusing on the mapping of roots or root-related processes [21]. For EIT studies of small-scale root zones in the laboratory, the aforementioned conventional strategies can be used for the moisture-conductivity calibrations with the effect of density, but the related processes remain relatively time-consuming and laborious, and there is still a lack 
of studies of the effects of moisture and density on complex conductivity and the related calibrations, especially for horticultural substrates.

In this paper, for the mapping of spatial moisture distributions in small-scale substrate root zones using electrical imaging, we present a promising and relatively convenient calibration method in which a specially designed fixture with static compaction function can be used to easily obtain the variable VWCs, dry densities and complex conductivities of the measured samples. The main aim of this study is to identify the feasibility and potential of the proposed approach. More specifically, the objectives are to (i) verify its ability to assess the effects of VWC and dry density on complex conductivity for porous materials, such as substrates, and (ii) investigate its performance to establish the required moisture-conductivity relations.

\section{Principles of Moisture-Conductivity Calibration for Substrate}

The electrical impedance is the measure of the conductive and capacitive properties of a medium. Generally, the complex-valued impedance $\hat{Z}(\omega)$ at a (angular) frequency $\omega=2 \pi f$ is given as follows:

$$
\hat{Z}(\omega)=\hat{U}(\omega) / \hat{I}(\omega)=|Z(\omega)| e^{i \varphi(\omega)}=Z^{\prime}(\omega)+i Z^{\prime \prime}(\omega),
$$

where $\hat{U}(\omega), \hat{I}(\omega),|Z(\omega)|, \varphi(\omega), Z^{\prime}(\omega), Z^{\prime \prime}(\omega)$ and $i=\sqrt{-1}$ are the voltage, the current, the impedance magnitude, the phase angle, the real part of the impedance, the imaginary part of the impedance, and the imaginary unit, respectively.

With the geometrical dimensions of the measurement being taken into account, the impedance can be translated to the "apparent" resistivity $\hat{\rho}_{\mathrm{a}}(\omega)=K \hat{Z}(\omega)$, where $K$ is the real-valued geometric factor. $\hat{\rho}_{\mathrm{a}}(\omega)$ measures the effective material characteristic, or even the true property, if the investigated medium is homogeneous [1,2,22,23,25]. Moreover, the inverse of $\hat{Z}(\omega)$ and $\hat{\rho}_{\mathrm{a}}(\omega)$ are the admittance $\hat{Y}(\omega)$ and the apparent conductivity $\hat{\sigma}_{\mathrm{a}}(\omega)$, respectively.

For an assumed homogeneous medium, such as soil, the conductivity $\hat{\sigma}(\omega)$ at certain low frequencies can be expressed as follows [26]:

$$
\hat{\sigma}(\omega)=\sigma^{\prime}(\omega)+\mathrm{i} \sigma^{\prime \prime}(\omega)=\left(\sigma_{\text {bulk }}+\sigma_{\text {surf }}^{\prime}(\omega)\right)+\mathrm{i} \sigma^{\prime \prime}{ }_{\text {surf }}(\omega),
$$

where $\sigma^{\prime}(\omega), \sigma^{\prime \prime}(\omega), \sigma_{\text {bulk }}, \sigma_{\text {surf }}^{\prime}(\omega)$, and $\sigma^{\prime \prime}$ surf $(\omega)$ are the in-phase conductivity, the quadrature conductivity, the bulk conductivity, the real part of the surface conductivity, and the imaginary part of the surface conductivity, respectively. To correlate the measured conductivity to the desired property, typically the VWC, various semi-empirical models have been developed [1,27-31]. For media, such as clean sands and coarsegrain soils, $\sigma_{\text {surf }}^{\prime}(\omega)$ is negligible [5,32], and the common model is the Archie equation $\sigma_{\text {bulk }}=a^{-1} \phi^{m}(\theta / \phi)^{n} \sigma_{\mathrm{w}}$ [27], where $a, \phi, \theta, S_{\mathrm{w}}=\theta / \phi, \sigma_{\mathrm{w}}, m$, and $n$ are the tortuosity, the porosity, the VWC, the water saturation, the pore water conductivity, the cementation exponent, and the saturation exponent, respectively. The dry density $\rho_{\mathrm{d}}$ can be related to $\phi$ by the relationship $\phi=1-\rho_{\mathrm{d}} / \rho_{\mathrm{s}}$, where $\rho_{\mathrm{s}}$ is the specific gravity [33]. For others (e.g., fine-textured soils, soils with high clay and silt contents) $[29,31,34]$, the common model is given as follows:

$$
\sigma^{\prime}=a^{-1} \phi^{m-n} \theta^{n} \sigma_{\mathrm{w}}+\sigma_{\mathrm{s}}^{\prime}\left(\phi, \theta, \sigma_{\mathrm{w}}\right),
$$

where the in-phase surface conductivity at a certain frequency $\sigma_{\mathrm{s}}^{\prime}$ is dependent on $\phi, \theta$ and $\sigma_{\mathrm{w}}$. In practice, the widely applied form with an assumed constant $\sigma_{\mathrm{s}}^{\prime}$ is expressed as $\sigma^{\prime}=A \theta^{n}+\sigma^{\prime}{ }_{\mathrm{s}}[5,35-38]$, where $A, n$ and $\sigma^{\prime}$ s are fitting parameters. Moreover, temperature corrections on conductivities are usually required, and the applied relation [13] is as follows:

$$
\sigma_{25}=\sigma_{\mathrm{T}} /[1+0.025(T-25)],
$$

where $\sigma_{25}$ and $\sigma_{\mathrm{T}}$ are the conductivities at $25^{\circ} \mathrm{C}$ and at temperature $T$, respectively. Additionally, for a specific medium with a constant $\sigma_{\mathrm{w}}$, the characterized electrical conductivity 
constitutive surface (ECCS) (Figure 1) can be used to analyze and assess the effects of the dry density $\rho_{\mathrm{d}}$ and the VWC $\theta$ on the conductivity $\sigma^{\prime}[20]$.

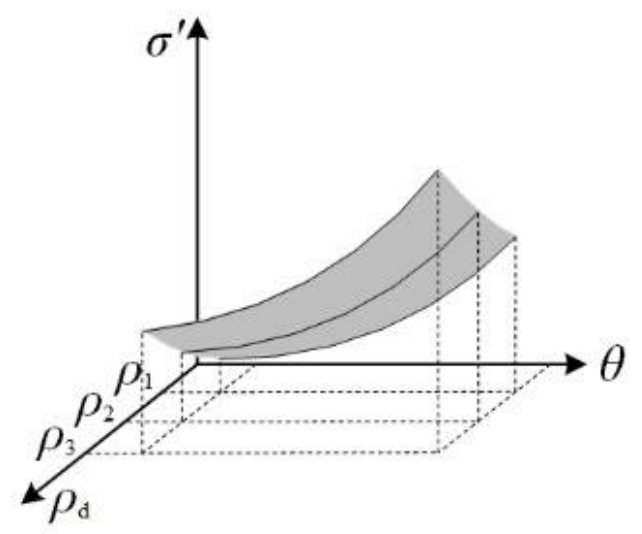

Figure 1. Schematic of an electrical conductivity constitutive surface (ECCS) to characterize in-phase conductivity $\sigma^{\prime}$ as a function of dry density $\rho_{\mathrm{d}}$ and volumetric water content $\theta$.

For porous media, such as soils, there exist equivalent circuit models to characterize the frequency dependence of the measured complex resistivity. One common model is shown in Figure 2, where $R_{1}$ and $Q_{1}$ model the contact resistance and double layer capacitance at the soil-electrode interface; $R_{2}, Q_{2}$, and $R_{4}$ represent the resistance, the capacitance and the shift resistance at the grain-boundary; and $R_{3}$ and $Q_{3}$ describe the grain interior conduction $[26,39]$. The constant phase element (CPE) $Q$ with the impedance $\hat{Z}(\omega)=1 / Q(i w)^{\alpha}$ is applied to represent a non-ideal capacitor, owing to the heterogeneities of the measured materials.

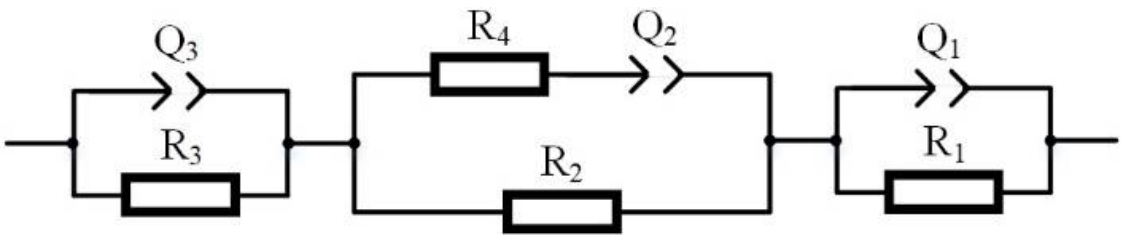

Figure 2. Equivalent circuit model for impedance analysis of porous materials, such as soils. The three circuit parts $\mathrm{Q}_{3} / / \mathrm{R}_{3},\left(\mathrm{R}_{4}+\mathrm{Q}_{2}\right) / / \mathrm{R}_{2}$ and $\mathrm{Q}_{1} / / \mathrm{R}_{1}$ model the resistive effects inside soil grains, related to the soil pore network and at the soil-electrode interface, respectively.

\section{Materials and Methods}

\subsection{Experimental Materials}

The experimental substrate was obtained from a mixture of peat soil, vermiculite and perlite (Beijing Zhongnong Futong Horticulture Co., Ltd., Beijing, China), and the volume ratio of these components was 3:1:1. Moreover, particles larger than $4.0 \mathrm{~mm}$ in diameter were filtered out with a sieve. Furthermore, other sieves with different pore diameters from $1.5 \mathrm{~mm}$ to $4.0 \mathrm{~mm}$ were used to measure the particle size distribution. Overall, for the different particle size ranges, i.e., $<1.5,1.5-2.0,2.0-2.5$, and $2.5-4.0 \mathrm{~mm}$, the corresponding volume ratios were $44.4 \%, 15.5 \%, 18.9 \%$, and $21.2 \%$, respectively. Moreover, the specific gravity of the substrate at $25^{\circ} \mathrm{C}$ was approximately $2.63 \mathrm{~g} / \mathrm{cm}^{3}$, which was determined by the average of three measurements, using pycnometer and kerosene based on the ASTM standard D854-14 [40].

\subsection{Measurement, Calculation and Characteristic Analysis}

First, the impedance measurements (Figure S1) of substrates at numerous dry densities (Table S1) and VWCs (Table S2) were performed. For more details of the related setup, procedures and conditions (e.g., the temperatures (Table S3)), please refer to the Supplementary Materials. Secondly, the conversions from the impedance spectra to the conductivity 
(or resistivity) spectra and the temperature corrections on conductivities were conducted, using the Microsoft Excel 2016 (Microsoft Corporation, Redmond, WA, USA). The related conversions and corrections were performed, using $\hat{\sigma}(\omega)=1 / \hat{\rho}(\omega)=L^{2} / V \hat{Z}(\omega)$, where $L, A$, and $V$ are the length, the area, and the volume of a measured sample, and Equation (4), respectively. Thirdly, the representations of the spectra (e.g., Nyquist plots, magnitude spectra, and phase spectra) and the equivalent circuit modelling were accomplished, using the EC-Lab software V11.16 (Bio-Logic Science Instruments Ltd., Grenoble, France) to conduct the related analyses and interpretations. For the substrate, to investigate the effect of moisture on the measured conductivity $\hat{\sigma}_{\text {meas }}$, several sets of spectra at different VWCs and nearly equal dry densities were picked out, and the spectral analysis and the comparison of equivalent circuit parameters (Figure 2) on each of these sets were performed. Moreover, to explore the effect of moisture on the substrate conductivity $\hat{\sigma}_{\text {subs }}$ (i.e., the conductivity of the substrate in itself), the resistive effect at the substrate-electrode interface (i.e., those of $Q_{1} / /$ $R_{1}$ ) was removed from each spectrum, and the conductive effect inside the substrate grains and related to the pore network was approximated as $\hat{\sigma}_{\text {subs }}$ and then, similar analyses and comparisons were conducted. In addition, the effects of density on $\hat{\sigma}_{\text {meas }}$ (or $\hat{\sigma}_{\text {subs }}$ ) were also inspected in a similar way. Finally, to identify the feasibility to establish the required moisture-conductivity relations for the substrate, the related curve and surface fits were performed, using the Curve Fitting Toolbox 3.5.6 (The MathWorks, Inc., Natick, MA, USA). For relatively homogeneous substrates (i.e., those sets at nearly constant density), the fits of moisture-conductivity curves at different frequencies were carried out. Furthermore, the fits of conductivity-moisture-density surfaces at different frequencies were conducted to assess the effects of moisture and density on conductivity. Additionally, for the substrates with certain variability in density, the fits of the moisture-conductivity curves at different frequencies were also performed.

\section{Results}

\subsection{Effect of Moisture on Complex Conductivity for Substrate}

For the substrate, to investigate the effect of the VWC $\theta$ on the measured complex conductivity $\hat{\sigma}_{\text {meas }}$ using two electrodes, several series of conductivity (or resistivity) spectra of the substrates at different VWCs and nearly equal dry densities were picked out, and then, the spectral analysis on each set of spectra was performed. One group of measured conductivity (or resistivity) spectra are exemplarily shown in Figure 3 (or Figure A1), and the related VWCs and dry densities are shown in Table 1. The mean and standard deviation of these dry densities (Table 1) are $0.398 \mathrm{~g} / \mathrm{cm}^{3}$ and $4.97 \times 10^{-3}$, respectively. As shown in Figure $3 \mathrm{~b}$,d, the conductivity amplitude $\left|\sigma_{\text {meas }}\right|$ and the in-phase conductivity $\sigma^{\prime}$ meas increase clearly and regularly as $\theta$ increases, and $\left|\sigma_{\text {meas }}\right|$ and $\sigma^{\prime}$ meas increase as the frequency increases. As shown in Figure $3 c$, the change in the phase $\varphi_{\text {meas }}$ with the increase in $\theta$ is relatively irregular, but the difference between the phases at different VWCs is relatively smallest in the frequency range around $10^{3} \mathrm{~Hz}$. As shown in Figure $3 \mathrm{e}$, the increase in the quadrature conductivity $\sigma^{\prime \prime}$ meas with the increase in $\theta$ is not as regular as those in $\left|\sigma_{\text {meas }}\right|$ and $\sigma_{\text {meas. }}^{\prime}$. Meanwhile, there are similar characteristics for the other sets of measured conductivity (or resistivity) spectra. Moreover, the above results (or characteristics) are basically consistent with those in the previous works [17,18]. Overall, for the substrate at relatively constant $\rho_{\mathrm{d}}$, the increase in $\theta$ mainly results in significant and regular increases in $\left|\sigma_{\text {meas }}\right|$ and $\sigma_{\text {meas. }}^{\prime}$. 


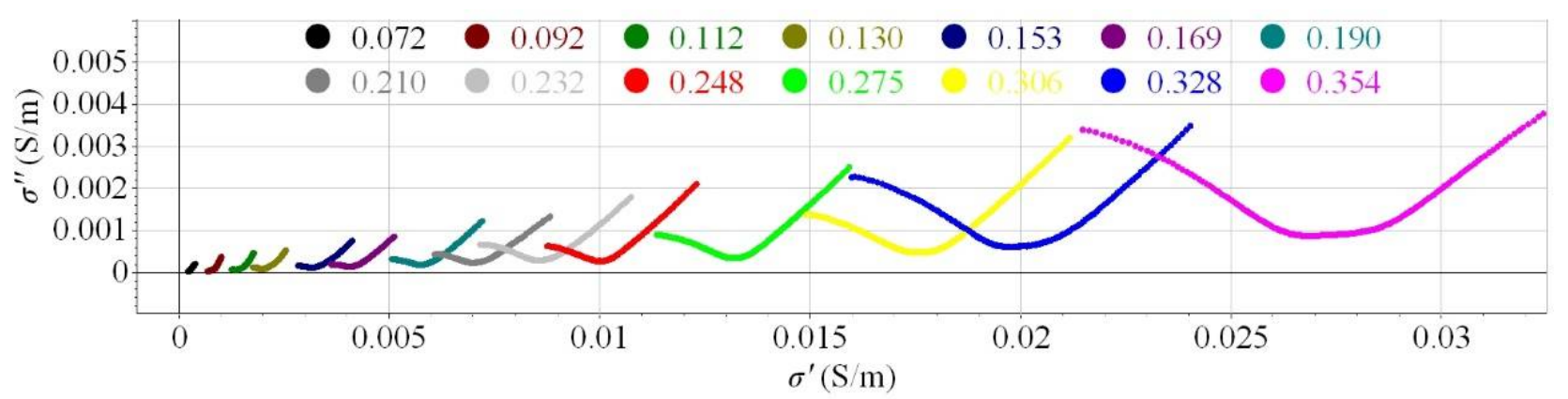

(a)

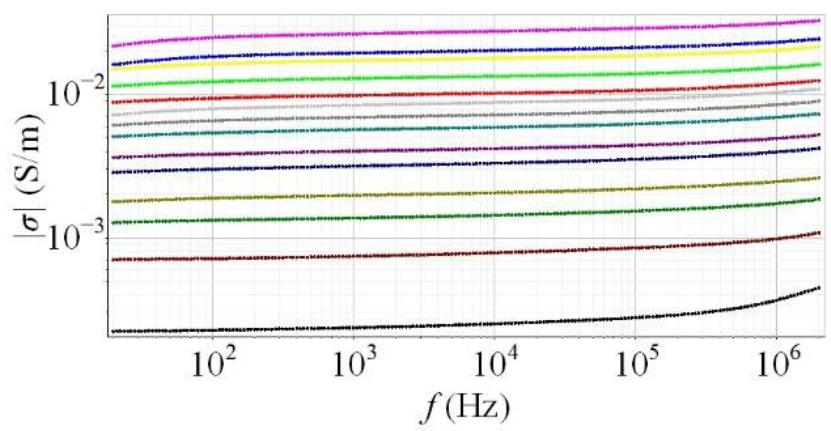

(b)

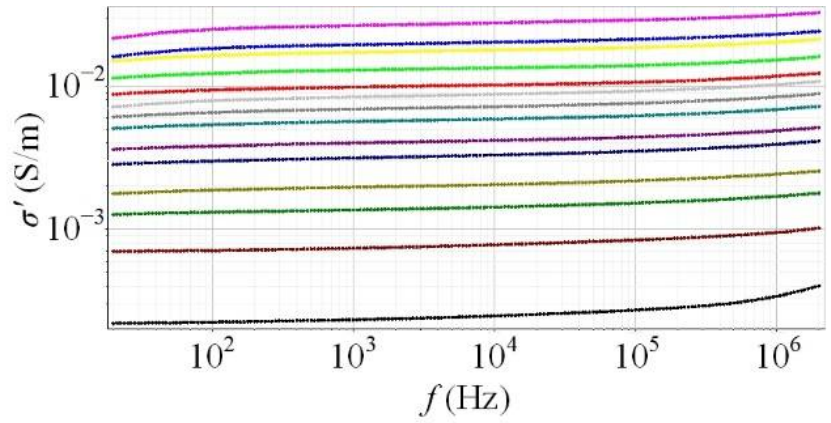

(d)

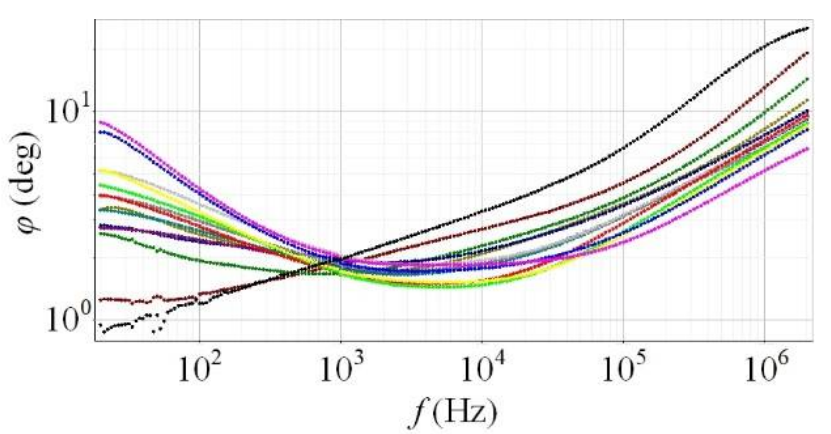

(c)

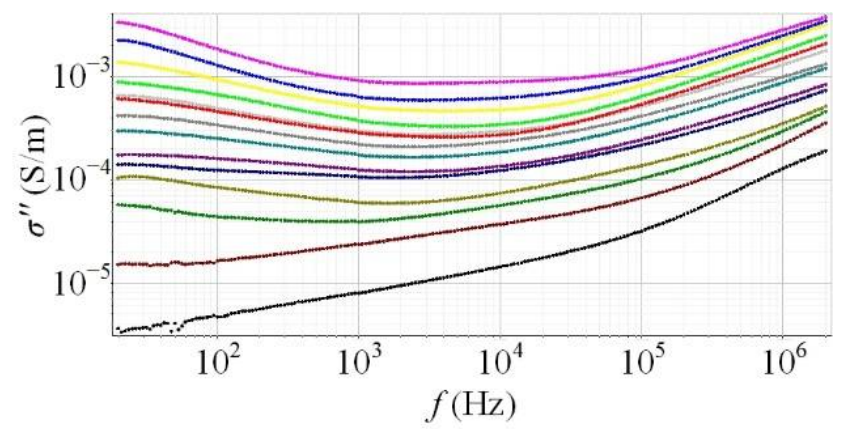

(e)

Figure 3. Impact of changes in volumetric water content on measured complex conductivity of substrate. (a) Nyquist plots; (b) magnitude spectra; (c) phase spectra; (d) in-phase conductivity spectra; (e) quadrature conductivity spectra. For the spectra marked by different colors, the variable volumetric water contents are provided in (a), while the related dry densities (Table 1) are considered to be nearly equal. The frequency range is from $20 \mathrm{~Hz}$ to $2 \mathrm{MHz}$.

Table 1. Volumetric water contents of a typical set of substrates at nearly equal dry densities *.

\begin{tabular}{lllllllllllllllll}
\hline \multicolumn{10}{c}{ Volumetric Water Content $\left(\mathbf{c m}^{3} / \mathbf{c m}^{3}\right)$} \\
\hline \multicolumn{11}{c}{ Dry Density $\left(\mathbf{g} / \mathbf{c m}^{3}\right)$} \\
\hline 0.396 & 0.396 & 0.397 & 0.396 & 0.401 & 0.395 & 0.397 & 0.396 & 0.392 & 0.393 & 0.393 & 0.405 & 0.407 & 0.405 \\
\hline 0.072 & 0.096 & 0.112 & 0.130 & 0.153 & 0.169 & 0.190 & 0.210 & 0.232 & 0.248 & 0.275 & 0.306 & 0.328 & 0.354 \\
\hline
\end{tabular}

* The mean and standard deviation of these dry densities are $0.398 \mathrm{~g} / \mathrm{cm}^{3}$ and $4.97 \times 10^{-3}$, respectively.

To inspect the cause of the increase in $\left|\sigma_{\text {meas }}\right|$ (or $\sigma^{\prime}$ meas) with increasing $\theta$, the comparison of equivalent circuit parameters on each set of spectra above were performed. For illustration, the equivalent circuit parameters for the set of spectra in Figure 3 are displayed in Table 2. As shown in Table 2, as $\theta$ increases, $Q_{3}, Q_{2}$ and $Q_{1}$ tend to increase, while $R_{3}$, $R_{4}, R_{2}$ and $R_{1}$ tend to decrease; this indicates that the conductive effects inside substrate 
grains, related to the substrate pore network and at the substrate-electrode interface, tend to increase (i.e., the resistive effects for $Q_{3} / / R_{3},\left(R_{4}+Q_{2}\right) / / R_{2}$ and $Q_{1} / / R_{1}$ tend to decrease). Moreover, for the equivalent circuit parameters of the other sets of spectra, there are similar features. Furthermore, the above results are basically consistent with those in the previous research [39]. In addition, the substrate at $\theta$ of $0.190 \mathrm{~cm}^{3} / \mathrm{cm}^{3}$ and $\rho_{\mathrm{d}}$ of $0.397 \mathrm{~g} / \mathrm{cm}^{3}$ is selected as an example to better understand the change in the measured resistivity $\rho_{\text {meas }}^{\prime}$ with frequency. The Nyquist plots for the substrate and its corresponding fitted equivalent circuit are shown in Figure $4 a$, and those for the three circuit parts $Q_{3}$ $/ / R_{3},\left(R_{4}+Q_{2}\right) / / R_{2}$ and $Q_{1} / / R_{1}$ are shown in Figure $4 b-d$, separately. As shown in Figure 4 , the decreases in the real components of the three parts with increasing frequency lead to the decrease in $\rho_{\text {meas }}^{\prime}$ with increasing frequency, and the resistive effect related to the substrate pore network with water (i.e., $\left.\left(\mathrm{R}_{4}+\mathrm{Q}_{2}\right) / / \mathrm{R}_{2}\right)$ plays a dominant influence on $\hat{\rho}_{\text {meas }}$ (or $\left.\hat{\sigma}_{\text {meas }}\right)$. Overall, for the substrate at relatively constant $\rho_{\mathrm{d}}$, the increase in $\theta$ can enhance the conductive effects inside the substrate grains, related to the substrate pore network and at the substrate-electrode interface; thus, it results in the increase in $\left|\sigma_{\text {meas }}\right|$ ( or $\sigma^{\prime}$ meas), and the conductive effect related to the substrate pore network filled with water plays a dominant role.

Table 2. Variation in equivalent circuit parameters of substrate affected by volumetric water content *.

\begin{tabular}{ccccccccccc}
\hline $\begin{array}{c}\text { VWC } \boldsymbol{\theta} \\
\left(\mathbf{c m}^{\mathbf{3}} / \mathbf{c m}^{\mathbf{3}} \mathbf{)}\right.\end{array}$ & $\begin{array}{c}\boldsymbol{Q}_{\mathbf{3}} \\
\mathbf{( F )}\end{array}$ & $\boldsymbol{\alpha}_{\mathbf{3}}$ & $\begin{array}{c}\boldsymbol{R}_{\mathbf{3}} \\
\mathbf{(} \mathbf{)}\end{array}$ & $\begin{array}{c}\boldsymbol{R}_{\mathbf{4}} \\
(\boldsymbol{\Omega})\end{array}$ & $\begin{array}{c}\boldsymbol{Q}_{\mathbf{2}} \\
\mathbf{( F )}\end{array}$ & $\boldsymbol{\alpha}_{\mathbf{2}}$ & $\begin{array}{c}\boldsymbol{R}_{\mathbf{2}} \\
(\boldsymbol{\Omega})\end{array}$ & $\begin{array}{c}\boldsymbol{Q}_{\mathbf{1}} \\
(\mathbf{F})\end{array}$ & $\begin{array}{c}\boldsymbol{\alpha}_{\mathbf{1}} \\
(\boldsymbol{\Omega})\end{array}$ \\
\hline 0.072 & $1.14 \times 10^{-6}$ & 0.699 & 188.9 & 1146 & $6.31 \times 10^{-10}$ & 0.798 & 3334 & $3.27 \times 10^{-5}$ & 0.305 \\
0.096 & $1.20 \times 10^{-5}$ & 0.511 & 209.4 & 54.96 & $2.81 \times 10^{-9}$ & 0.725 & 1139 & $1.21 \times 10^{-3}$ & 0.328 & 183.0 \\
0.112 & $1.72 \times 10^{-5}$ & 0.530 & 97.49 & 22.95 & $8.66 \times 10^{-9}$ & 0.673 & 634.8 & $1.10 \times 10^{-3}$ & 0.477 & 205.9 \\
0.130 & $1.95 \times 10^{-5}$ & 0.514 & 62.76 & 4.714 & $2.36 \times 10^{-8}$ & 0.620 & 435.4 & $1.62 \times 10^{-3}$ & 0.400 & 332.7 \\
0.153 & $3.41 \times 10^{-5}$ & 0.547 & 19.92 & 50.14 & $9.58 \times 10^{-8}$ & 0.565 & 273.0 & $4.92 \times 10^{-3}$ & 0.222 & 400.8 \\
0.169 & $8.81 \times 10^{-5}$ & 0.616 & 4.598 & 3.170 & $5.37 \times 10^{-7}$ & 0.473 & 233.8 & $3.53 \times 10^{-3}$ & 0.330 & 114.6 \\
0.190 & $9.82 \times 10^{-5}$ & 0.591 & 5.617 & 10.44 & $4.32 \times 10^{-7}$ & 0.507 & 164.2 & $4.63 \times 10^{-3}$ & 0.357 & 106.9 \\
0.210 & $1.85 \times 10^{-3}$ & 0.673 & 29.81 & 18.19 & $1.40 \times 10^{-6}$ & 0.449 & 135.3 & $7.90 \times 10^{-3}$ & 0.244 & 29.40 \\
0.232 & $9.00 \times 10^{-4}$ & 0.856 & 19.81 & 9.018 & $9.62 \times 10^{-7}$ & 0.485 & 110.1 & $8.73 \times 10^{-3}$ & 0.251 & 44.82 \\
0.248 & $2.88 \times 10^{-3}$ & 0.903 & 5.034 & 3.696 & $8.48 \times 10^{-7}$ & 0.500 & 96.98 & $1.47 \times 10^{-2}$ & 0.279 & 117.6 \\
0.275 & $5.38 \times 10^{-3}$ & 0.761 & 4.679 & 4.849 & $1.09 \times 10^{-6}$ & 0.496 & 74.03 & $1.92 \times 10^{-2}$ & 0.294 & 263.0 \\
0.306 & $2.32 \times 10^{-3}$ & 0.772 & 15.52 & 10.41 & $9.64 \times 10^{-7}$ & 0.518 & 55.06 & $7.50 \times 10^{-2}$ & 0.369 & 7.847 \\
0.328 & $8.90 \times 10^{-3}$ & 0.941 & 14.59 & 12.92 & $5.00 \times 10^{-7}$ & 0.562 & 44.85 & $2.13 \times 10^{-2}$ & 0.180 & 22.83 \\
0.354 & $1.17 \times 10^{-3}$ & 0.930 & 13.17 & 51.31 & $9.29 \times 10^{-8}$ & 0.677 & 31.06 & $1.78 \times 10^{-2}$ & 0.177 & 15.96 \\
\hline
\end{tabular}

${ }^{*}$ For the variable volumetric water contents (VWCs), the related dry densities (Table 1) are considered to be nearly equal. As shown in Figure $2, Q_{3} / / R_{3},\left(R_{4}+Q_{2}\right) / / R_{2}$ and $Q_{1} / / R_{1}$ represent the resistive effects inside substrate grains, related to the substrate pore network and at the substrate-electrode interface, respectively.

To investigate the effect of the VWC $\theta$ on the substrate conductivity $\hat{\sigma}_{\text {subs }}$, several sets of conductivity (or resistivity) spectra of the substrates at nearly equal dry densities and different VWCs were picked out, and the spectral analysis and the comparison of equivalent circuit parameters on each set of spectra were conducted. One set of substrate conductivity (or resistivity) spectra are exemplarily shown in Figure 5 (or Figure A2). The related equivalent circuit parameters can be found in Table 2, and the corresponding VWCs and dry densities are shown in Table 1 . Overall, the characteristics for the change in $\hat{\sigma}_{\text {subs }}$ with the increase in $\theta$ are similar to those for $\hat{\sigma}_{\text {meas }}$, i.e., the increase in $\theta$ primarily leads to the obvious and regular increase in $\left|\sigma_{\text {subs }}\right|$ and $\sigma_{\text {subs, }}^{\prime}$ and the conductive effect related to the substrate pore network filled with water plays a leading role; these results are relatively consistent with those in the previous studies [13-15]. 


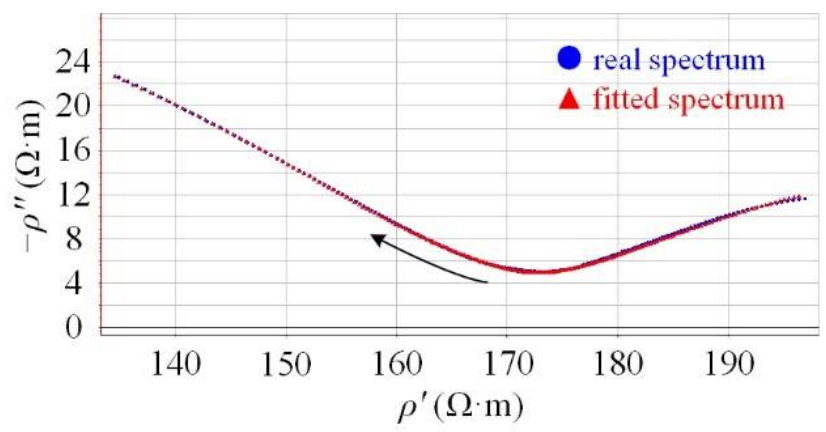

(a)

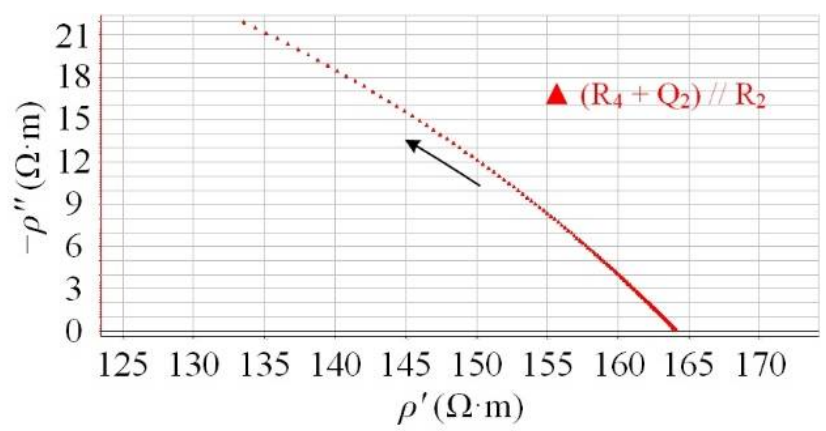

(c)

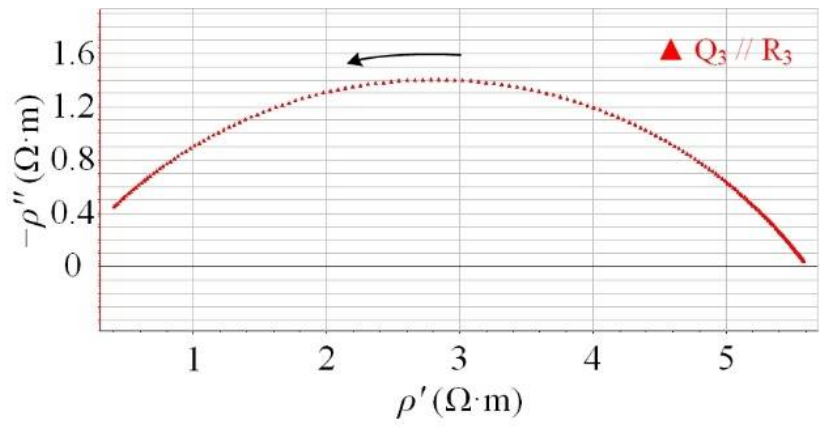

(b)

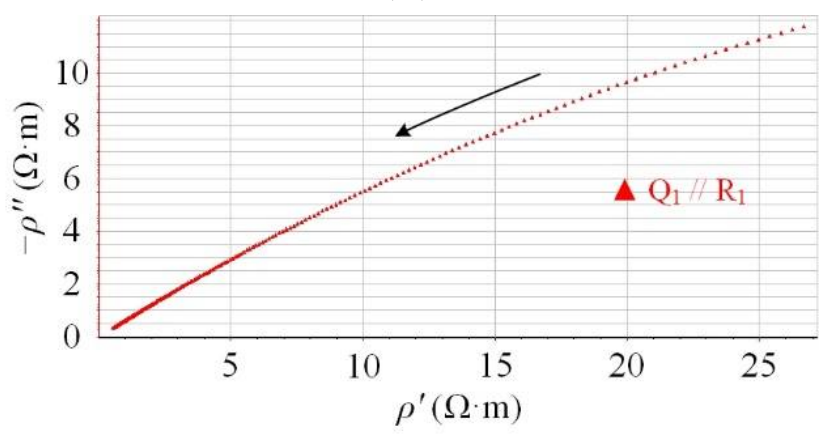

(d)

Figure 4. Nyquist plots for the measured resistivity of a typical substrate sample, the corresponding equivalent circuit and its three parts. (a) Fitted spectrum well matched with the real (or measured) spectrum; (b) $Q_{3} / / R_{3} ;(c)\left(R_{4}+Q_{2}\right) / /$ $\mathrm{R}_{2} ;$ (d) $\mathrm{Q}_{1} / / \mathrm{R}_{1}$. The substrate is at the volumetric water content of $0.190 \mathrm{~cm}^{3} / \mathrm{cm}^{3}$ and dry density of $0.397 \mathrm{~g} / \mathrm{cm}^{3}$. The frequency range is from $20 \mathrm{~Hz}$ to $2 \mathrm{MHz}$, and the direction of an arrow indicates that of frequency increase. As shown in Figure $2, Q_{3} / / R_{3},\left(R_{4}+Q_{2}\right) / / R_{2}$ and $Q_{1} / / R_{1}$ denote the resistive effects inside substrate grains, related to the substrate pore network and at the substrate-electrode interface, respectively.

\subsection{Effect of Density on Complex Conductivity for Substrate}

To explore the variation of the measured complex conductivity $\hat{\sigma}_{\text {meas }}$ with the dry density $\rho_{\mathrm{d}}$ for the substrate, the spectral analyses upon several sample sets at different $\rho_{\mathrm{d}}$ and nearly constant $\theta$ were performed. One typical series of conductivity spectra are presented in Figure 6, while the related resistivity spectra as well as the VWCs and dry densities are provided in Figure A3 and Table 3, respectively. The mean and standard deviation of these VWCs (Table 3) are $0.231 \mathrm{~cm}^{3} / \mathrm{cm}^{3}$ and $7.93 \times 10^{-3}$, respectively. As shown in Figure $6 \mathrm{~b}, \mathrm{~d}$, the conductivity magnitude $\left|\sigma_{\text {meas }}\right|$ and the in-phase conductivity $\sigma^{\prime}$ meas increase obviously and regularly as $\rho_{\mathrm{d}}$ increases. Moreover, the increases in $\left|\sigma_{\text {meas }}\right|$ and $\sigma^{\prime}$ meas with the increase in frequency in the middle frequency range are relatively gentler than those in the lower and higher frequency ranges. However, as shown in Figure $6 \mathrm{c}$, the change in the phase $\varphi_{\text {meas }}$ with the increase in $\rho_{\mathrm{d}}$ is relatively irregular, and, as shown in Figure 6e, the increase in the quadrature conductivity $\sigma^{\prime \prime}$ meas with the increase in $\rho_{\mathrm{d}}$ is not as regular as those in $\left|\sigma_{\text {meas }}\right|$ and $\sigma^{\prime}$ meas. Meanwhile, similar features for the other sets of measured conductivity (or resistivity) spectra were also observed. Overall, for the substrate at relatively constant $\theta$, the increase in $\rho_{\mathrm{d}}$ mainly causes the obvious and regular increases in $\left|\sigma_{\text {meas }}\right|$ and $\sigma_{\text {meas }}^{\prime}$. 


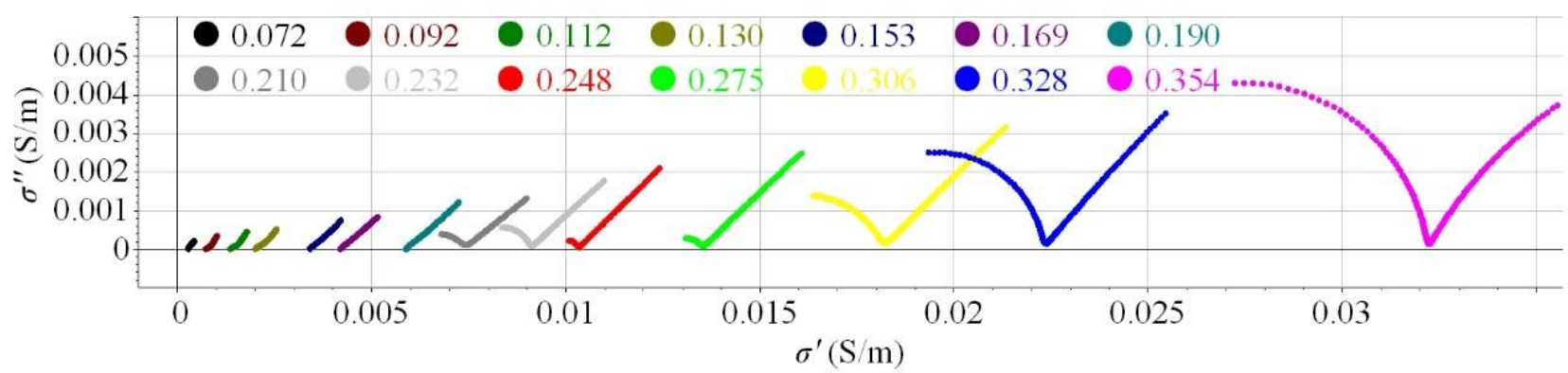

(a)

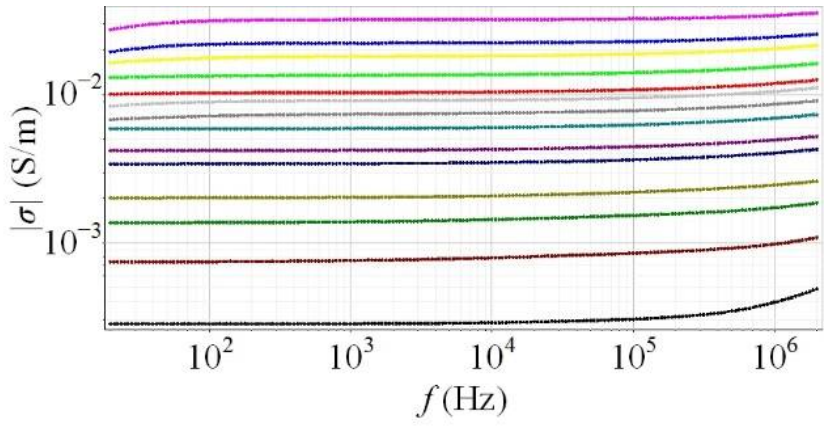

(b)

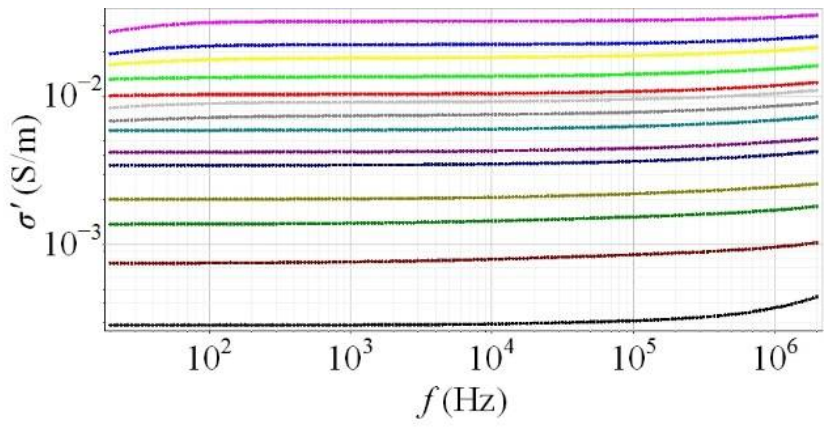

(d)

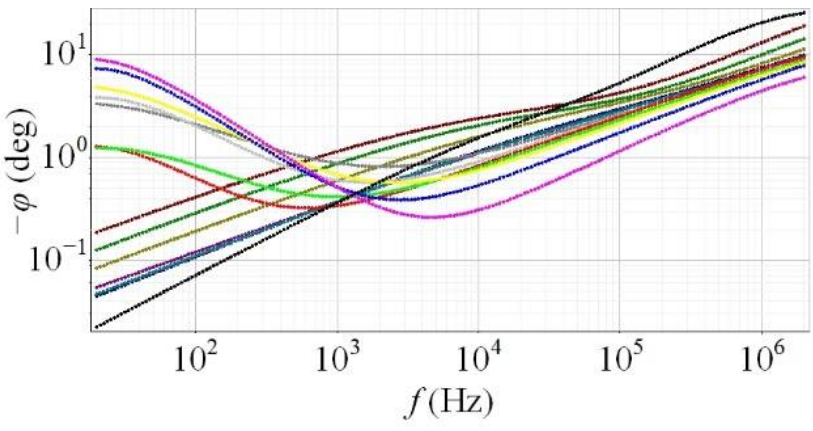

(c)

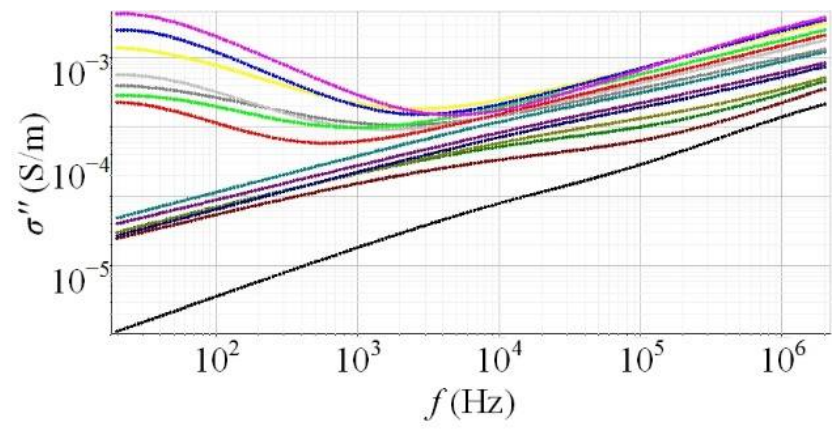

(e)

Figure 5. Impact of changes in volumetric water content on complex conductivity spectra of substrate. (a) Nyquist plots; (b) magnitude spectra; (c) phase spectra; (d) in-phase conductivity spectra; (e) quadrature conductivity spectra. For the spectra marked by different colors, the variable volumetric water contents are provided in (a), while the related dry densities (Table 1) are considered to be nearly equal. The frequency range is from $20 \mathrm{~Hz}$ to $2 \mathrm{MHz}$.

To analyze the source of the increase in $\left|\sigma_{\text {meas }}\right|$ (or $\sigma^{\prime}$ meas $)$ with increasing $\rho_{\mathrm{d}}$, the comparison of equivalent circuit parameters on each group of spectra above were conducted. The equivalent circuit parameters for the group of spectra in Figure 6 are exemplarily presented in Table 4. As shown in Table 4, as $\rho_{\mathrm{d}}$ increases, $\mathrm{Q}_{3}$ and $\mathrm{Q}_{2}$ tend to increase, while $R_{3}, R_{4}$ and $R_{2}$ tend to decrease; this indicates that the conductive effects inside substrate grains and related to the substrate pore network tend to increase (i.e., the resistive effects for $\mathrm{Q}_{3} / / \mathrm{R}_{3}$ and $\left(\mathrm{R}_{4}+\mathrm{Q}_{2}\right) / / \mathrm{R}_{2}$ tend to decrease). Furthermore, unlike the geometric factors for the sets of parameters in Table 2, those in Table 4 are not approximately equal, and thus, the trend for the change of the conductive effect at the substrate-electrode interface with the increase in $\rho_{\mathrm{d}}$ is not analyzed. Meanwhile, similar features for the equivalent circuit parameters of the other sets of spectra were also observed. Overall, for the substrate at relatively constant $\theta$, the increase in $\rho_{\mathrm{d}}$ can improve the conductive effects inside substrate grains and related to the substrate pore network filled with water; thus, it contributes to the increase in $\left|\sigma_{\text {meas }}\right|$ (or $\sigma_{\text {meas }}^{\prime}$ ). 


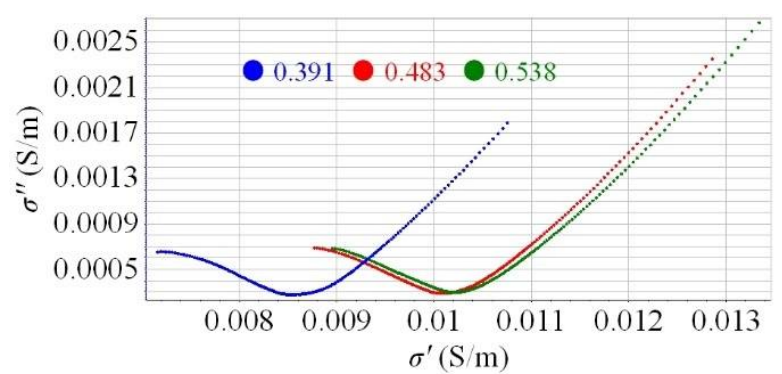

(a)

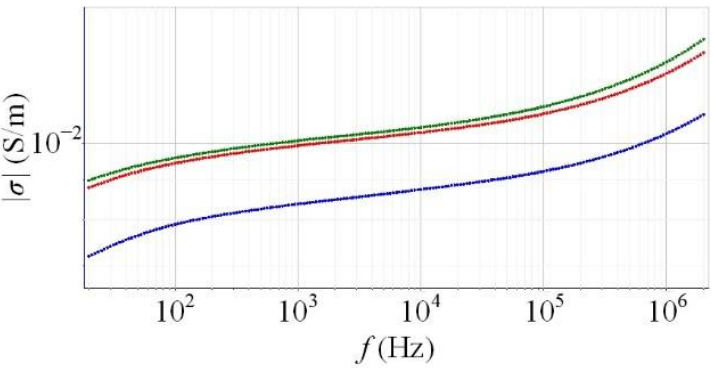

(b)

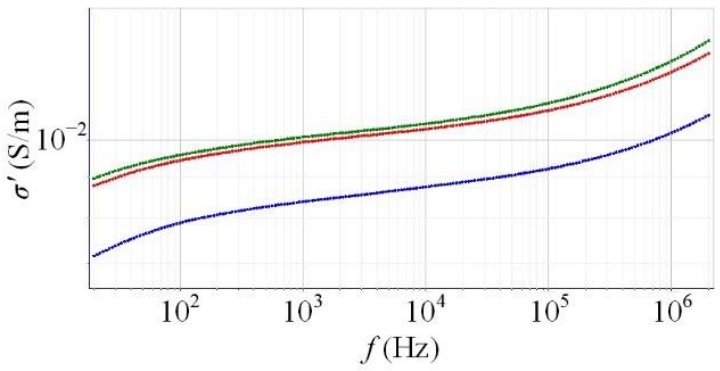

(d)

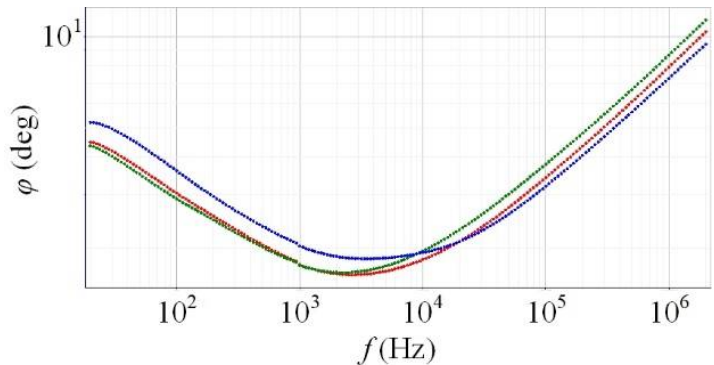

(c)

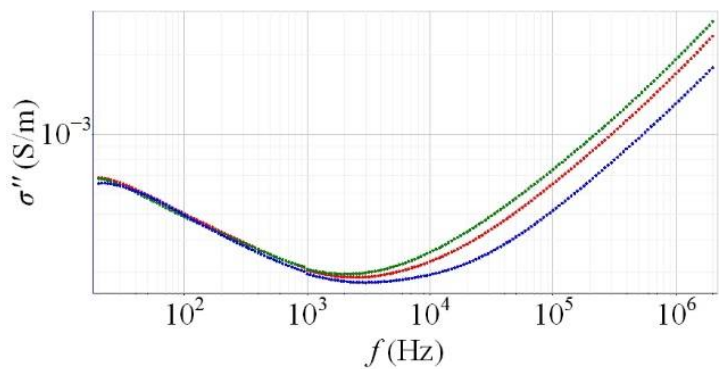

(e)

Figure 6. Impact of changes in dry density on measured complex conductivity of substrate. (a) Nyquist plots; (b) magnitude spectra; (c) phase spectra; (d) in-phase conductivity spectra; (e) quadrature conductivity spectra. For the spectra marked by different colors, the variable dry densities are provided in (a), while the related volumetric water contents (Table 3) are considered to be nearly equal. The frequency range is from $20 \mathrm{~Hz}$ to $2 \mathrm{MHz}$.

Table 3. Dry densities of a typical set of substrates at nearly equal volumetric water contents *

\begin{tabular}{ccc}
\hline \multicolumn{3}{c}{ Dry Density $\left(\mathrm{g} / \mathrm{cm}^{3}\right)$} \\
\hline & Volumetric Water Content $\left(\mathrm{cm}^{3} / \mathrm{cm}^{3}\right)$ & \\
\hline 0.232 & 0.231 & 0.230 \\
\hline 0.391 & 0.483 & 0.538 \\
\hline
\end{tabular}

* The mean and standard deviation of these VWCs (Table 3) are $0.231 \mathrm{~cm}^{3} / \mathrm{cm}^{3}$ and $7.93 \times 10^{-3}$, respectively.

Table 4. Variation in equivalent circuit parameters of substrates affected by dry density *.

\begin{tabular}{|c|c|c|c|c|c|c|c|c|c|c|}
\hline $\begin{array}{c}\rho_{\mathrm{d}} \\
\left(\mathrm{g} / \mathrm{cm}^{3}\right)\end{array}$ & $\begin{array}{l}Q_{3} \\
\text { (F) }\end{array}$ & $\alpha_{3}$ & $\begin{array}{c}R_{3} \\
(\Omega)\end{array}$ & $\begin{array}{c}R_{4} \\
(\Omega)\end{array}$ & $\begin{array}{l}Q_{2} \\
(\mathrm{~F})\end{array}$ & $\alpha_{2}$ & $\begin{array}{c}R_{2} \\
(\Omega)\end{array}$ & $\begin{array}{l}Q_{1} \\
\text { (F) }\end{array}$ & $\alpha_{1}$ & $\begin{array}{c}R_{1} \\
(\Omega)\end{array}$ \\
\hline 0.391 & $9.00 \times 10^{-4}$ & 0.856 & 19.81 & 9.018 & $9.62 \times 10^{-7}$ & 0.485 & 110.1 & $8.73 \times 10^{-3}$ & 0.251 & 44.82 \\
\hline 0.483 & $1.80 \times 10^{-3}$ & 0.795 & 17.55 & 8.050 & $1.10 \times 10^{-6}$ & 0.493 & 93.36 & $1.21 \times 10^{-2}$ & 0.238 & 29.83 \\
\hline 0.538 & $2.18 \times 10^{-3}$ & 0.857 & 11.58 & 4.111 & $1.62 \times 10^{-6}$ & 0.477 & 93.01 & $1.67 \times 10^{-2}$ & 0.233 & 63.58 \\
\hline
\end{tabular}

${ }^{*}$ For the variable dry densities, the related volumetric water contents (Table 3) are considered to be nearly equal. As shown in Figure $2, \mathrm{Q}_{3}$ $/ / R_{3},\left(R_{4}+Q_{2}\right) / / R_{2}$ and $Q_{1} / / R_{1}$ represent the resistive effects inside substrate grains, related to the substrate pore network and at the substrate-electrode interface, respectively. 
To inspect the effect of the dry density $\rho_{\mathrm{d}}$ on the substrate conductivity $\hat{\sigma}_{\text {subs, }}$, several sets of conductivity (or resistivity) spectra of the substrates at nearly equal VWCs and different dry densities were picked out, and the spectral analysis and the comparison of equivalent circuit parameters on each set of spectra were conducted. For illustration, one set of substrate conductivity (or resistivity) spectra are shown in Figure 7 (or Figure A4); the related equivalent circuit parameters can be found in Table 4, and the corresponding VWCs and dry densities are shown in Table 3. Overall, the properties for the change in $\hat{\sigma}_{\text {subs }}$ with the increase in $\rho_{\mathrm{d}}$ are similar to those in $\hat{\sigma}_{\text {meas }}$, i.e., the increase in $\rho_{\mathrm{d}}$ primarily results in the clear and regular increase in $\left|\sigma_{\text {subs }}\right|$ and $\sigma_{\text {subs, }}^{\prime}$ and the conductive effect related to the substrate pore network with water plays a dominant role; these results are relatively consistent with those in the previous research $[19,20]$.

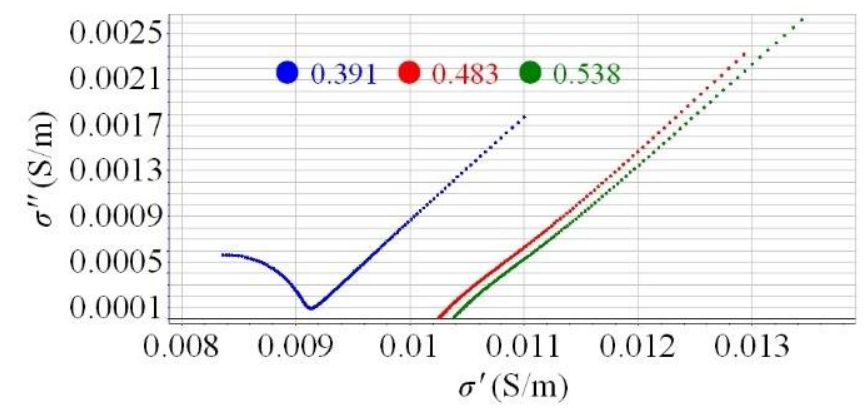

(a)

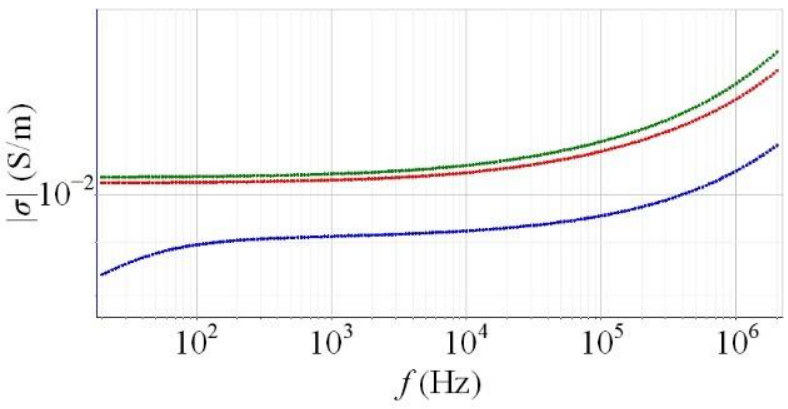

(b)

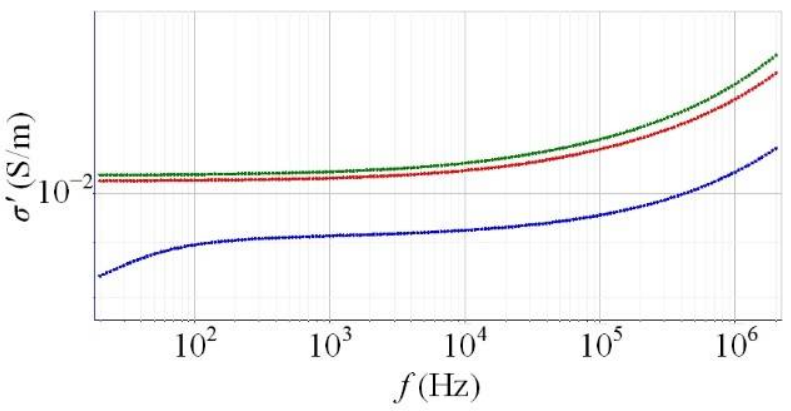

(d)

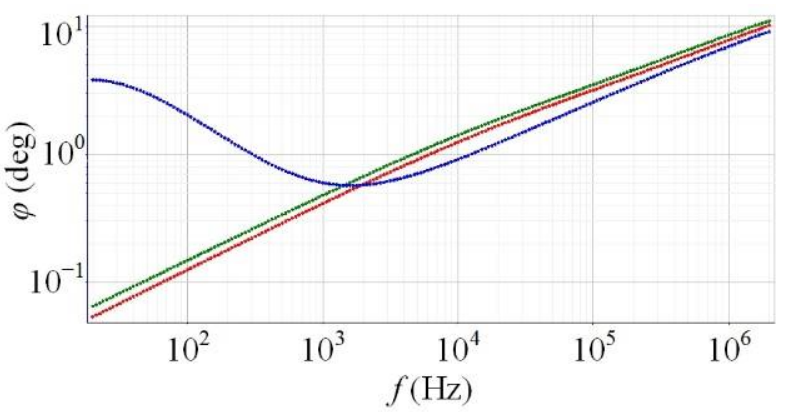

(c)

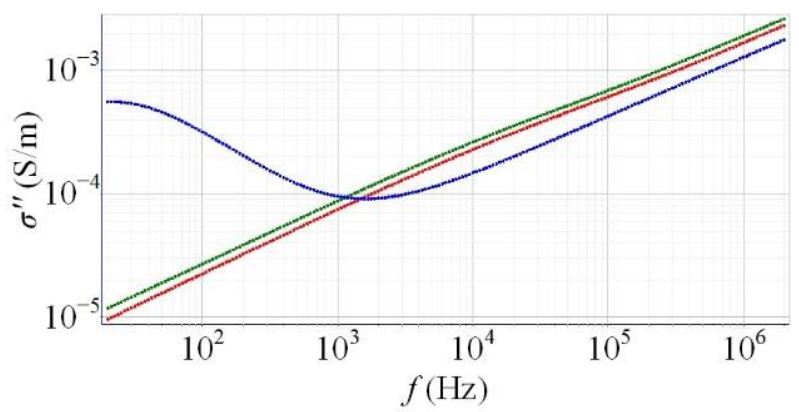

(e)

Figure 7. Impact of changes in dry density on complex conductivity of substrate. (a) Nyquist plots; (b) magnitude spectra; (c) Phase spectra; (d) in-phase conductivity spectra; (e) quadrature conductivity spectra. For the spectra marked by different colors, the variable dry densities are provided in (a), while the related volumetric water contents (Table 3) are considered to be nearly equal. The frequency range is from $20 \mathrm{~Hz}$ to $2 \mathrm{MHz}$. 


\subsection{Relationship between Electrical Conductivity and Moisture for Substrate}

For artificially compacted and relatively homogeneous substrates (i.e., those at nearly constant $\rho_{\mathrm{d}}$ ), to investigate the feasibility of development of relations between $\sigma_{\text {subs }}^{\prime}$ (or $\left.\left|\sigma_{\text {subs }}\right|\right)$ and $\theta$ at different frequencies, the related curve fits based on $\sigma^{\prime}=a \theta^{b}+c$ for several sets of substrates at nearly equal dry densities and different VWCs were performed. For the exemplary set of substrates at nearly constant $\rho_{\mathrm{d}}$ of $0.398 \mathrm{~g} / \mathrm{cm}^{3}$ (Table 1 ), the fitted $\sigma_{\text {subs }}^{\prime}-\theta$ relations at different frequencies are shown in Figure 8, and the results show that there are good power-law correlations $\left(R^{2} \geq 0.99\right)$ between $\sigma^{\prime}$ subs and $\theta$ at different frequencies. Moreover, there are similar results for the fitted $\left|\sigma_{\text {subs }}\right|-\theta$ curves at different frequencies (Figure A5). Furthermore, for the other sets of substrates at relatively constant $\rho_{\mathrm{d}}$, similar results can also be achieved for the related fits between $\sigma^{\prime}$ subs $\left(\right.$ or $\left|\sigma_{\text {subs }}\right|$ ) and $\theta$ at different frequencies. Overall, for the substrates at nearly constant $\rho_{\mathrm{d}}$, good powerlaw calibration relations between $\sigma_{\text {subs }}^{\prime}$ (or $\left.\left|\sigma_{\text {subs }}\right|\right)$ and $\theta$ can be established at different frequencies.

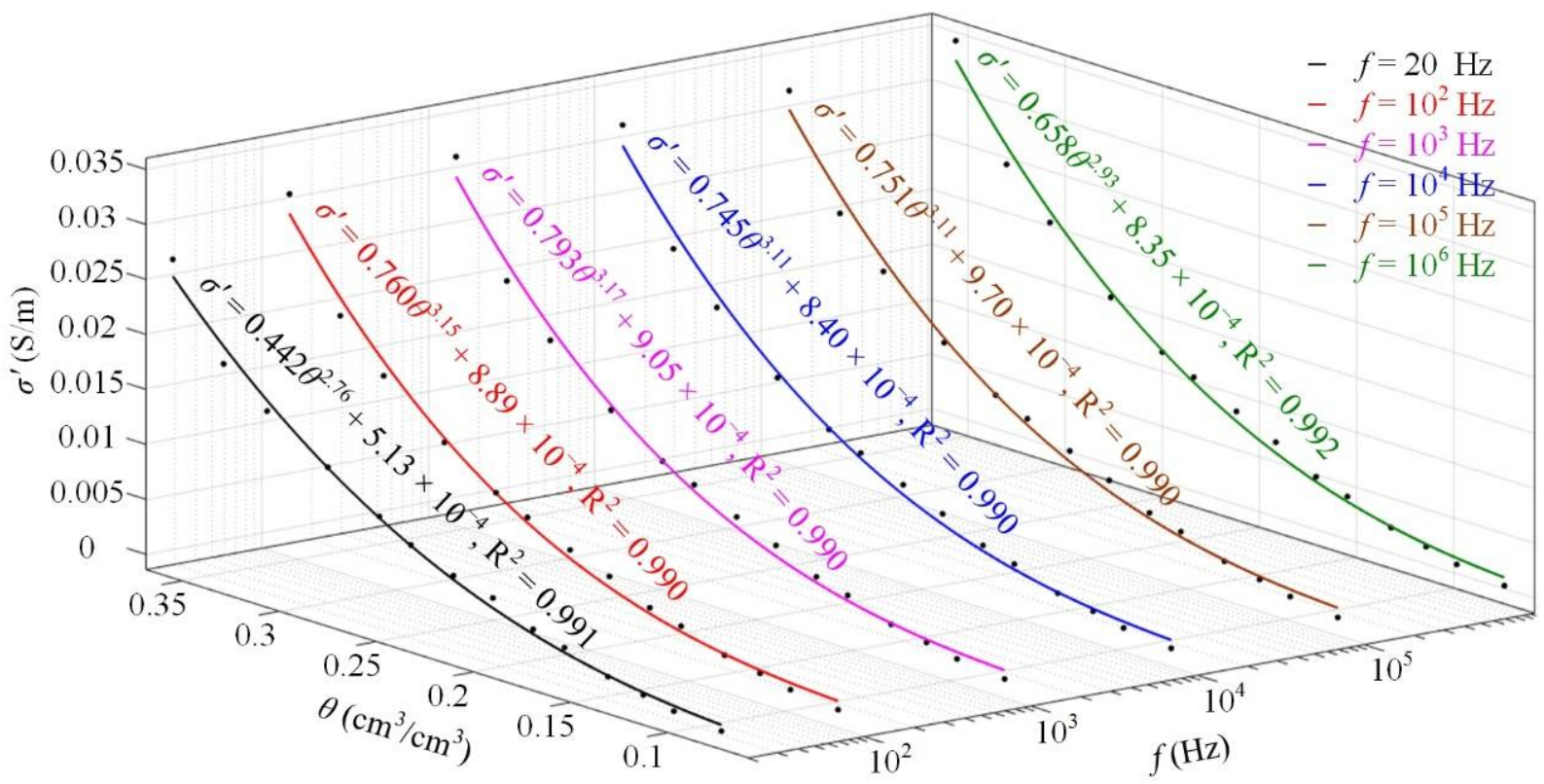

Figure 8. Fitted relations between in-phase substrate conductivity and volumetric water content at different frequencies for a typical set of substrates at nearly equal dry densities. The mean and standard deviation of the related dry densities (Table 1) are $0.398 \mathrm{~g} / \mathrm{cm}^{3}$ and $4.97 \times 10^{-3}$, respectively.

For the substrate, to explore the relationships among $\sigma_{\text {subs }}^{\prime}$ (or $\left.\left|\sigma_{\text {subs }}\right|\right), \theta$ and $\rho_{\mathrm{d}}$ at different frequencies as well as assess the effect of $\rho_{\mathrm{d}}$ and $\theta$ on $\sigma^{\prime}$ subs (or $\left.\left|\sigma_{\text {subs }}\right|\right)$, the related surface fits based on $\sigma^{\prime}=a\left(1-\rho_{d} / \rho_{s}\right)^{b} \theta^{c}+d$ for the substrates at different VWCs and dry densities were performed. The fitted $\sigma^{\prime}$ subs $-\theta-\rho_{\mathrm{d}}$ relation $\left(R^{2}=0.99\right)$ at $1 \mathrm{kHz}$ is shown in Figure 9, where $\rho_{s}=2.63$. The fitted surface shows that at constant $\rho_{\mathrm{d}}, \sigma_{\text {subs }}^{\prime}$ increases as $\theta$ increases, while at constant $\theta, \sigma^{\prime}$ subs increases as $\rho_{\mathrm{d}}$ increases. Moreover, for the substrate, compared with the rate of $\sigma^{\prime}$ subs change with $\theta$ (i.e., $\partial \sigma^{\prime}$ subs $/ \partial \theta$ ), the rate of $\sigma^{\prime}$ subs change with $\rho_{\mathrm{d}}$ (i.e., $\partial \sigma^{\prime}$ subs $/ \partial \rho_{\mathrm{d}}$ ) is relatively small. Furthermore, there are similar results for the fitted $\left|\sigma_{\text {subs }}\right|-\theta-\rho_{\mathrm{d}}$ relation at $1 \mathrm{kHz}$ (Figure A6). Meanwhile, similar results can be obtained for the related curve fits at other frequencies. Overall, for the substrate, good power-law relations among $\sigma_{\text {subs }}^{\prime}$ (or $\left.\left|\sigma_{\text {subs }}\right|\right), \theta$ and $\rho_{\mathrm{d}}$ at different frequencies can be established, and both the increases in $\theta$ and $\rho_{\mathrm{d}}$ can cause an increase in $\sigma_{\text {subs }}^{\prime}$ (or $\left|\sigma_{\text {subs }}\right|$ ), but, compared to $\partial \sigma_{\text {subs }}^{\prime} / \partial \theta$ (or $\partial\left|\sigma_{\text {subs }}\right| / \partial \theta$ ), $\partial \sigma_{\text {subs }}^{\prime} / \partial \rho_{\mathrm{d}}$ (or $\partial\left|\sigma_{\text {subs }}\right| / \partial \rho_{\mathrm{d}}$ ) is relatively small. 


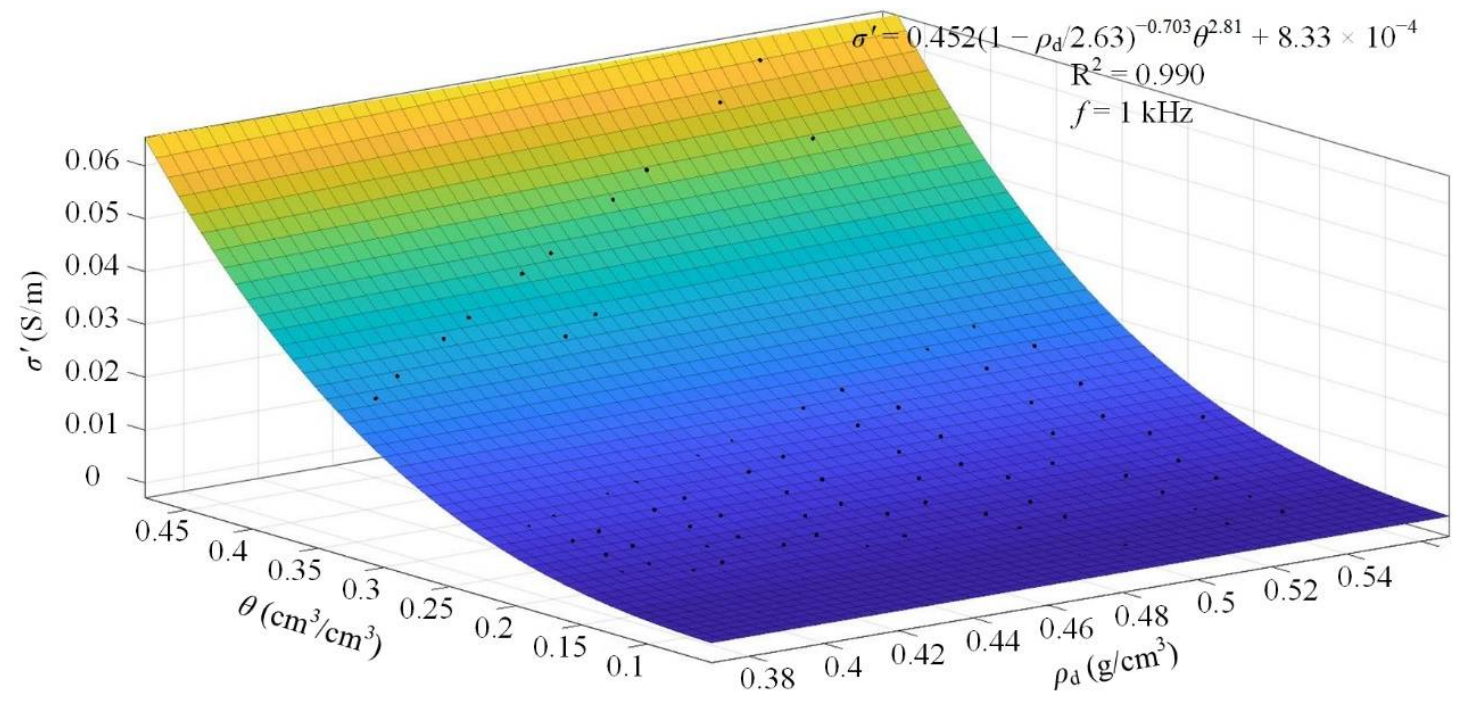

Figure 9. Fitted relation for in-phase substrate conductivity as a function of volumetric water content and dry density at the frequency of $1 \mathrm{kHz}$. The related dry densities and VWCs are shown in Tables S1 and S2, respectively.

For substrates with certain variability in dry density, to study the feasibility of establishment of relations between $\sigma_{\text {subs }}^{\prime}$ (or $\left|\sigma_{\text {subs }}\right|$ ) and $\theta$ at different frequencies, the related curve fits based on $\sigma^{\prime}=a \theta^{b}+c$ for the substrates at different VWCs and dry densities were performed. For the substrates with the mean of $0.455 \mathrm{~g} / \mathrm{cm}^{3}$ and the standard deviation of $5.04 \times 10^{-2}$ in dry density (Table S1), the fitted $\sigma_{\text {subs }}^{\prime}-\theta$ relations at different frequencies are shown in Figure 10, and the results show good power-law correlations $\left(R^{2} \geq 0.99\right)$ between $\sigma^{\prime}$ subs and $\theta$ at different frequencies. Moreover, similar results can be achieved for the $\left|\sigma_{\text {subs }}\right|-\theta$ fits at different frequencies (Figure A7). Overall, for the substrate, compared with $\theta, \rho_{\mathrm{d}}$ has a relatively small effect on $\sigma^{\prime}$ subs (or $\left.\left|\sigma_{\text {subs }}\right|\right)$, and thus, for the substrates with certain variability in dry density, good power-law calibration curves between $\sigma^{\prime}$ subs (or $\left.\left|\sigma_{\text {subs }}\right|\right)$ and $\theta$ at different frequencies can be established.

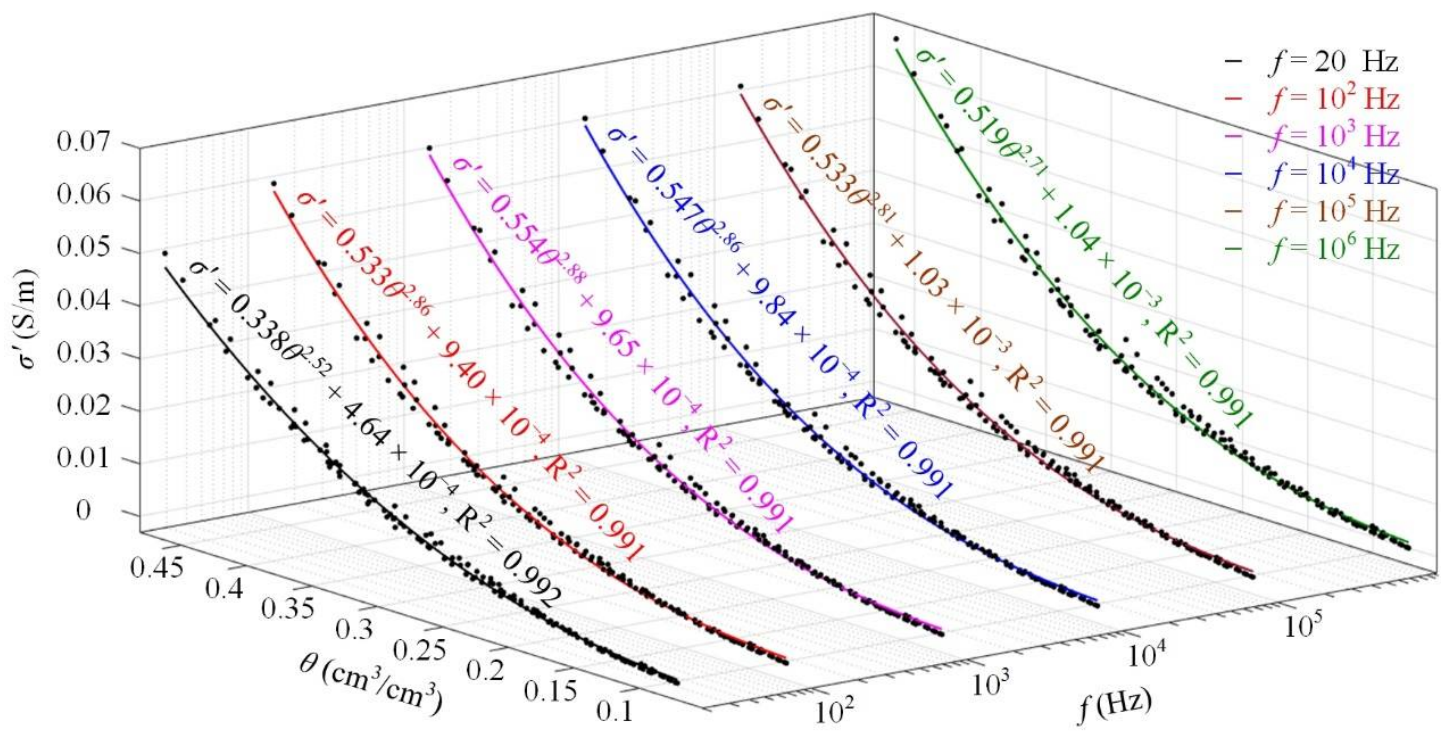

Figure 10. Fitted relations between in-phase substrate conductivity and volumetric water content at different frequencies for the substrates with certain variability in dry density. The mean and standard deviation of the dry densities (Table S1) are $0.455 \mathrm{~g} / \mathrm{cm}^{3}$ and $5.04 \times 10^{-2}$, respectively. 


\section{Discussion}

In this work, through the calibration method, using a fixture with static compaction function, the variable dry densities from $0.379 \mathrm{~g} / \mathrm{cm}^{3}$ to $0.559 \mathrm{~g} / \mathrm{cm}^{3}$ (Table S1), the various VWCs from $0.070 \mathrm{~cm}^{3} / \mathrm{cm}^{3}$ to $0.462 \mathrm{~cm}^{3} / \mathrm{cm}^{3}$ (Table S2) and the related conductivity spectra from $20 \mathrm{~Hz}$ to $2 \mathrm{MHz}$ for the measured substrates were easily provided. Next, the spectral analysis and comparison of equivalent circuit parameters on each set of spectra at nearly equal dry densities were performed to investigate the effect of moisture on conductivity; the effect of density on conductivity was also analyzed in a similar way. The results show that the increase in VWC (or dry density) can increase the in-phase conductivity (or conductivity amplitude), primarily because of the improvement in the dominant pore water connectivity. Furthermore, at different frequencies, the conductivity-moisture-density surfaces were fitted to assess the effects of moisture and density on conductivity; the fits of moistureconductivity curves for the substrates with certain variability in density (Table S1) were performed. The results show that, for the substrates, compared to VWC, dry density has a relatively small effect on conductivity, and thus, good power-law moisture-conductivity curves $\left(R^{2} \geq 0.99\right)$ at different frequencies can be established.

In studies of root zones using electrical imaging to map the spatial moisture dynamics, to establish a required calibration relation between moisture and conductivity (i.e., the conductivity of an underground medium in itself), different strategies are available. In the traditional laboratory strategy, a sample cell called the test (or soil) box is commonly used, and the preparation of samples at numerous VWCs (or water saturations) is necessary. In addition, to minimize the difference between the density of boxed samples and that of an imaged domain, relatively complex and strict packing work is also required [3,4]. In another laboratory strategy $[7,8]$, or the related SIP studies of variably saturated soils $[6,12,15]$, the gradual desaturation (or saturation) and related conductivity measurements of an undisturbed (or disturbed) sample can be conveniently performed, but a relatively complex system, using a specially designed cell and an air injection apparatus, is demanded. In a more practical field strategy, each imaged domain or investigated site must be equipped with the related conductivity and moisture sensors. However, for EIT studies of laboratoryand small-scale substrate root zones, there are differences in dry density between different containers as well as between different spatial locations in a container; thus, to establish a moisture-conductivity relation for the substrates with variability in dry density, the use of one of the above strategies requires relatively laborious and time-consuming preparation and packing work, a relatively complex system, or related sensors for each site. Therefore, this paper presents a promising and relatively convenient laboratory calibration method. In this approach, the volumes of the samples at a series of (gravimetric) water contents can be changed, using the specially designed fixture with static compaction function; thus, the variable VWCs, dry densities and related conductivities can be easily obtained. The feasibility of the proposed method was confirmed, and, for porous media (e.g., substrates, soils), it was also shown the potential to assess the effects of VWC and dry density on complex conductivity as well as establish the moisture-conductivity relations at different frequencies with the effect of density variability. In addition, the application of a moistureconductivity relation for the mapping of moisture in a substrate zone using electrical imaging is exemplarily shown in Figure A8. As shown in Figure A8a, the experimental setup includes three parts, i.e., a cylindrical vessel with 16 external and 8 internal electrodes, a measuring device, and a computer for image reconstructions. The substrate zone in the vessel (Figure A8b) was measured using the equipment at $1 \mathrm{kHz}$, and then, the image of conductivity distribution (Figure A8c) was reconstructed, using the absolute imaging algorithm based on the Gauss-Newton method in the Electrical Impedance and Diffuse Optical Reconstruction Software (EIDORS) (http:/ / eidors3d.sourceforge.net/ (accessed on 17 September 2021)) [41]. Finally, the image of moisture distribution (Figure A8d) was obtained, using the related curve $|\sigma|=0.554 \theta^{2.88}+9.65 \times 10^{-4}$ at $1 \mathrm{kHz}$ (Figure A7). Moreover, the measuring device was a 32-channel serial data acquisition system, and it consisted of an EVAL-ADUCM350EBZ board and two matrix switch boards. Additionally, 
the optimal hyperparameter (i.e., regularization parameter) $\lambda=1.20 \times 10^{-2}$ (Figure A8c) was selected, using the L-curve method.

Although the spatial moisture distribution in a substrate zone can be achieved based on the established calibration curve, there remain many limitations. First of all, the use of the LCR meter and two-electrode method was a compromise. For conductivity measurements in the frequency range from $\mathrm{mHz}$ to $\mathrm{kHz}$, the use of two-electrode method can result in unacceptably large effects from electrode polarization, and thus, the fourelectrode method and a related integrated dedicated device are commonly applied [42,43]. For conductivity measurements in the frequency range from $\mathrm{kHz}$ to $\mathrm{MHz}$, the use of the four-electrode method can lead to errors from capacitive coupling between different parts of a setup (e.g., wires and electrodes); however, with the use of the two-electrode method and a LCR meter or impedance analyzer, these errors can be corrected through a short/open measurement [42,43]. Thus, in this study, mainly taking the required relatively wider frequency range into consideration, the two-electrode setup using a LCR meter was applied, and the effects of electrode polarization (or contact impedance) were removed through the equivalent circuit modelling. However, the removal of electrode polarization in this way can cause the removal of a part of the material polarization, and thus, for wideband conductivity measurements, the combination of four- and two-electrode methods with a specific correction procedure may be a better choice [42]. Secondly, seeking a set of compressed samples at nearly equal VWCs was not as easy as seeking a set of those at nearly equal dry densities, and it brought difficulties in assessing the effect of dry density on complex conductivity under the condition of relatively constant VWC. This is because the increments of approximately $5 \%$ in (gravimetric) water content were relatively large, and the change in VWC caused by the changes in volume of 2 or $4 \mathrm{~mL}$ was not continuous enough. Thus, samples with relatively smaller increments in (gravimetric) water content should be prepared, and a fixture with a smaller scale in volume or even an accurate displacement-controlled loading system [20] is required to achieve more continuous changes in VWC. Moreover, these practices can also provide more compressed samples with different VWCs and dry densities and thus, are helpful to establish more robust moisture-conductivity relations. Thirdly, the appearance and gradually increased volumes of spherical substrate blocks due to the continuous mixing procedure are harmful to this study. In the procedure where the (gravimetric) water content of the substrate with an initial weight of approximately $2 \mathrm{~kg}$ was gradually increased, to make the moisture distribution as uniform as possible, a spraying process was conducted, and a mixing process was simultaneously implemented. However, when the water content reached $59.3 \%$, the appearance of small spherical substrate blocks was noticed, and these blocks became larger as the mixing process was continued; this was also part of the reason why the experimental process ended when the water content reached $87.5 \%$. Obviously, the presence and gradually increased volumes of substrate blocks mean the differences in pore structure. Therefore, to avoid the appearance of the above blocks, it is better to provide a more advanced method to uniformly increase the water content without a mixing process.

Soil (or horticultural substrate) is a multi-phase, porous and particulate medium, and it consists of solid particles and pores filled with air, water, or both. For materials such as soils and substrates, the water phase is usually the main conductive path, and thus, the conductivity is generally dependent on the water content, salinity, connectivity in the pore network, and conduction on the particle surface [20]. As the water content increases, the pore water connectivity is improved, and thus, the conductivity increases $[17,19,20]$. The results in this study indicate that the magnitude of complex conductivity and the in-phase conductivity follow good power-law relations with the VWC, and these results are consistent with those in the previous works [11-15]. Moreover, the results in the previous studies also show a relatively regular relationship $[12,15]$ or good power-law function $[11,13,14]$ that the quadrature conductivity increases with the increase in saturation (or VWC), but this work does not show good results that are consistent with those in the previous studies, probably due to the following reasons. On the one hand, in this study, 
although a set of compressed substrates with nearly equal dry densities could be offered, the presence and different volumes of spherical substrate blocks produced by the continuous mixing process led to the relatively large differences in pore structure, while in the previous works, the sample desaturation using an air injection device $[12,15]$ or the related sample preparation $[11,13,14]$ caused relatively small differences in the pore structure. On the other hand, the removal of electrode polarization through the equivalent circuit modelling method can result in the removal of a part of the material polarization. Furthermore, in the related laboratory studies, $\mathrm{NaCl}$ solutions $[11,13,14]$ or tap water $[6,12,14]$ are usually applied, and tap water was used in this study. The released ions from the soluble salts in substrates could increase the pore water conductivity, but the extent to which this occurred is unknown and thus, was not considered, i.e., it was assumed that the pore water conductivities for all substrate samples were equal [12]. For soils, in general, the in-phase conductivity increases slightly as the frequency increases $[11,13,14]$. However, for soils such as sand-biochar mixtures, the increase in the in-phase conductivity with increasing frequency at a high saturation level and in the low frequency range of about $10^{-2}$ to $10^{2} \mathrm{~Hz}$ was relatively strong because of the stronger electrical double layer (EDL) polarization from the biochars under the related circumstances [15]. Similarly, for the substrate in this work, the increase in the in-phase conductivity (or conductivity amplitude) with frequency at a high VWC and in the low frequency range of about $10^{1}$ to $10^{2} \mathrm{~Hz}$ (or at a low VWC and in the high frequency range of about $10^{5}$ to $10^{6} \mathrm{~Hz}$ ) was relatively strong, due to the strong EDL and Maxwell-Wagner polarization from the substrate in the related situations. As the dry density increases, the number and area of the contacts between particles as well as the pore water connectivity are both enhanced, and therefore, the conductivity increases $[19,20]$. To a certain extent, the results in this work also show the relationship that the magnitude of complex conductivity and the in-phase conductivity increase with the increasing dry density. For mixtures such as soils and horticultural substrates, the rates of conductivity change with VWC and dry density depend on factors such as the mixture type, VWC and dry density [20]. For the substrate, compared with the rate of (in-phase) conductivity change with VWC, that with dry density is relatively small. Thus, for the substrates with certain variability in dry density, good power-law calibration curves between the in-phase conductivity (or conductivity amplitude) and VWC at different frequencies can be established. In the previous electrical imaging studies of root zones based on the simplified model $\sigma^{\prime}=A \theta^{n}+\sigma_{\text {surf }}^{\prime}[5,35,37,38,44,45]$, the ranges of the fitted values for the parameters $n$ and $\sigma^{\prime}$ surf are $1.04-5.40$ and $10^{-6}-10^{-2}$, respectively, while in this work, those in Figures 8 and 10 are 2.52-3.17 and $10^{-4}-10^{-3}$, respectively. Therefore, although the substrate in this study is indeed different from the soils in these previous works, the fitted $n$ and $\sigma^{\prime}$ surf values for the substrate are within reasonable ranges.

Overall, the mapping of spatial moisture dynamics in soil- or substrate-based root zones using electrical imaging is meaningful for fields such as water management and crop breeding in agriculture; there has been an increasing number of related studies or applications in recent years [1,2]. Moreover, moisture-conductivity calibration is the necessary foundation for each related application, but that using a conventional method is relatively laborious or complicated. Thus, to reduce the related calibration efforts and then allow the related applications to better focus on root-related dynamics, a relatively convenient calibration approach was proposed, and the related results have demonstrated its feasibility and potential to establish the essential moisture-conductivity curves. Although many further efforts remain required to improve the method, we hope that this work provides a reference for time- and labor-saving calibration strategies.

\section{Conclusions}

In the present work, the proposed method using static compaction can provide the required diverse VWCs, dry densities and related conductivity spectra of the measured substrates. From the spectral analyses, at nearly constant dry density, the increase in VWC primarily causes the increase in conductivity amplitude (or in-phase conductivity), while at 
relatively unchanging VWC, the increase in dry density also mainly leads to the increase in the conductivity amplitude (or in-phase conductivity). Moreover, the investigations using equivalent circuit modelling indicate that the enhanced conductive effect related to the connectivity of pore water plays a dominant effect on the above increases in conductivity with increasing VWC (or dry density). Furthermore, the related conductivity-moisturedensity relations suggest that for the substrate, the conductivity amplitude (or in-phase conductivity) is more sensitive to VWC, compared with dry density. Thus, in terms of the substrates having certain variability in dry density, the conductivity amplitudes (or in-phase conductivities) at different frequencies can follow good power-law functions $\left(R^{2} \geq 0.99\right)$ with VWC. Overall, for the mapping of moisture distribution in small-scale substrate root zones, the proposed approach exhibits its feasibility, convenience and potential in the assessment of the effects of factors (e.g., VWC, dry density) on conductivity and the establishment of essential moisture-conductivity calibration curves. For further research, we will focus on the improvement of the method of the lab analysis, the applicability of the data acquisition system, the extension in the amount of dry density and VWC values, and the validity on more types of soils and substrates.

Supplementary Materials: The following are available online at https:/ / www.mdpi.com/article/ 10.3390/agriculture11090899/s1, Figure S1: Impedance measurement of substrate sample using two-electrode method with controllable dry density and volumetric water content. (a) Photograph of the measurement setup; (b) schematic of the two-electrode measurement; (c) photograph of the user-fabricated sample fixture, Table S1: Dry densities of the compressed substrates for each moisture content, Table S2: Volumetric water contents of the compressed substrates for each moisture content, Table S3: Temperatures of the compressed substrates for each moisture content.

Author Contributions: Conceptualization, P.-F.Z., Z.-Y.W., Q.C. and L.H.; methodology, P.-F.Z.; software, P.-F.Z.; validation, P.-F.Z.; formal analysis, P.-F.Z.; investigation, P.-F.Z.; resources, P.-F.Z., L.-F.F., Y.-Q.W., Y.L. and N.W.; data curation, P.-F.Z.; writing-original draft preparation, P.-F.Z.; writing - review and editing, P.-F.Z., Z.-Y.W., Q.C. and L.H.; visualization, P.-F.Z.; supervision, Z.-Y.W. and L.H.; project administration, Z.-Y.W. and L.H.; funding acquisition, Z.-Y.W., Q.C. and L.H. All authors have read and agreed to the published version of the manuscript.

Funding: This research was funded by the Beijing Municipal Natural Science Foundation, grant number 6192016, the National Natural Science Foundation of China, grant number 31771671, and the National Key Research and Development Program of China, grant number 2016YFD0300304.

Institutional Review Board Statement: Not applicable.

Informed Consent Statement: Not applicable.

Data Availability Statement: The data that support this study will be shared upon reasonable request to the corresponding author.

Conflicts of Interest: The authors declare no conflict of interest. 


\section{Appendix A}

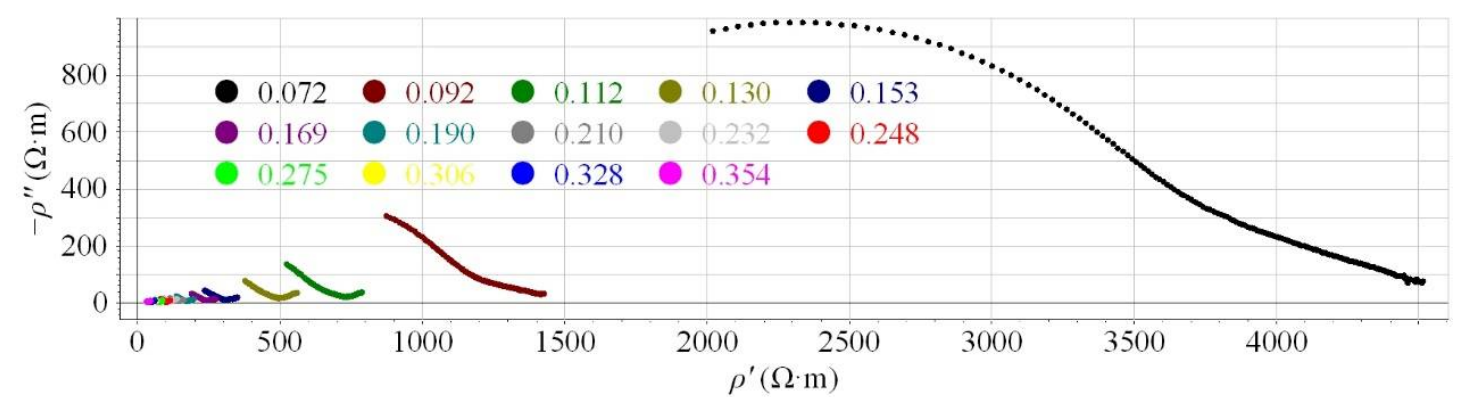

(a)

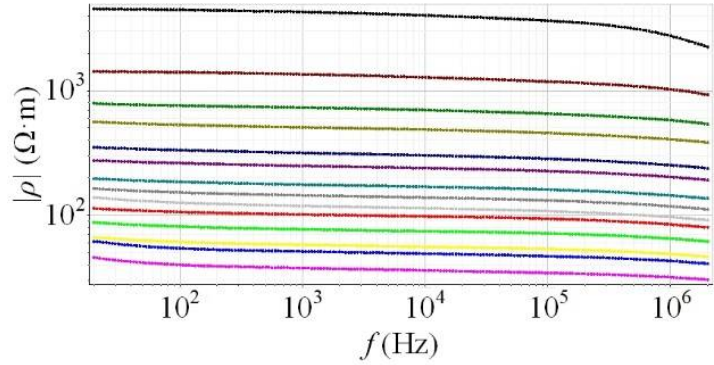

(b)

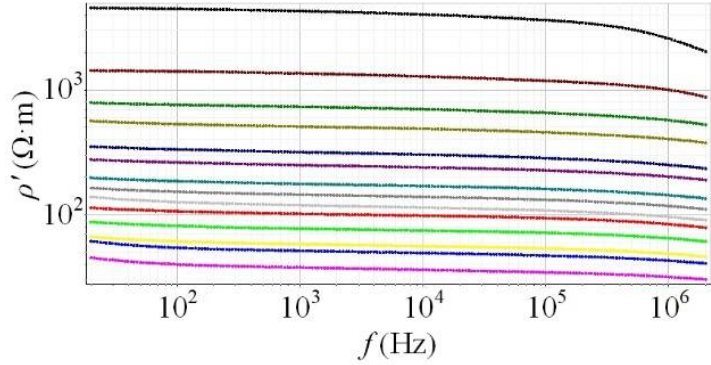

(d)

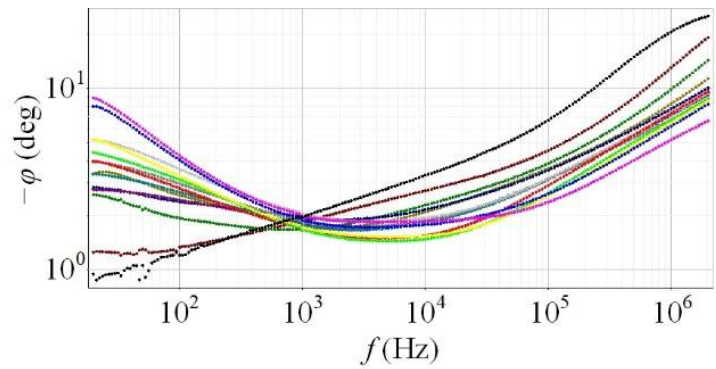

(c)

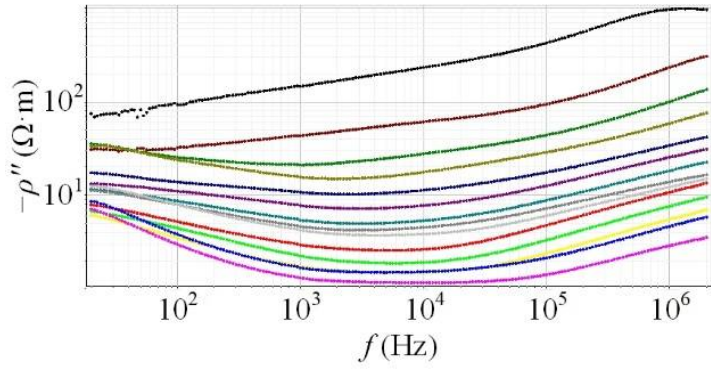

(e)

Figure A1. Impact of changes in volumetric water content on measured complex resistivity of substrate. (a) Nyquist plots; (b) magnitude spectra; (c) phase spectra; (d) in-phase conductivity spectra; (e) quadrature conductivity spectra. For the spectra marked by different colors, the variable volumetric water contents are provided in (a), while the related dry densities (Table 1) are considered to be nearly equal. The frequency range is from $20 \mathrm{~Hz}$ to $2 \mathrm{MHz}$.

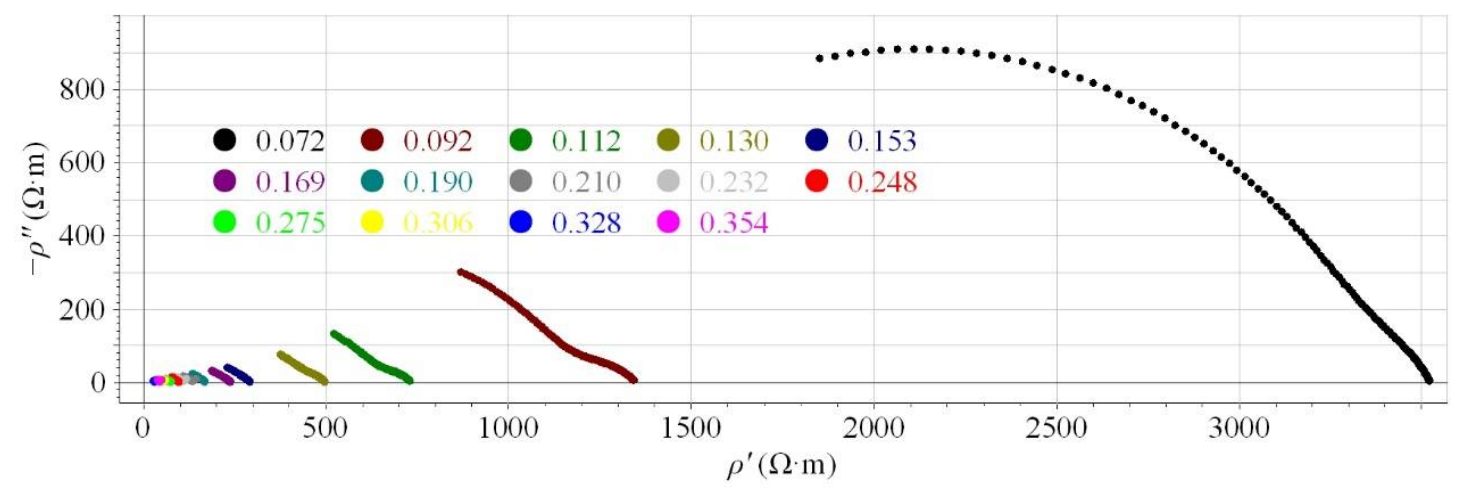

(a)

Figure A2. Cont. 


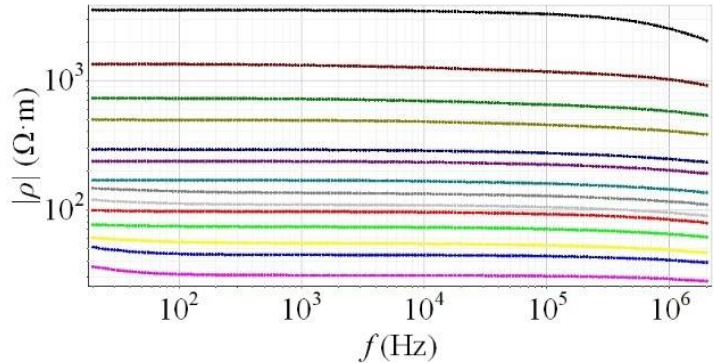

(b)

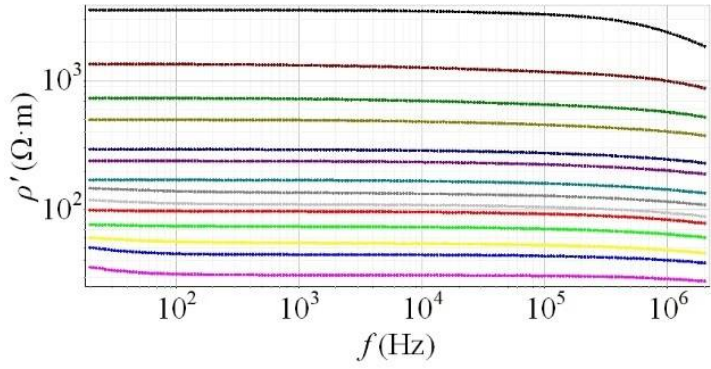

(d)

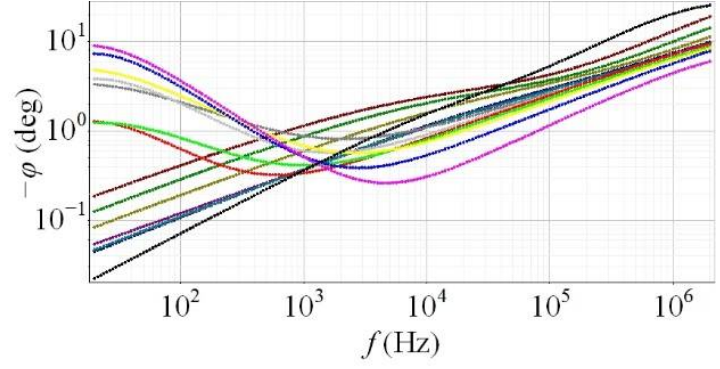

(c)

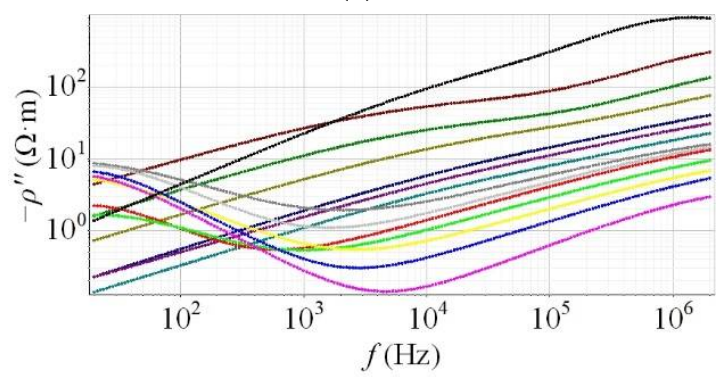

(e)

Figure A2. Impact of changes in volumetric water content on complex resistivity of substrate. (a) Nyquist plots; (b) magnitude spectra; (c) phase spectra; (d) in-phase conductivity spectra; (e) quadrature conductivity spectra. For the spectra marked by different colors, the variable volumetric water contents are provided in (a), while the related dry densities (Table 1) are considered to be nearly equal. The frequency range is from $20 \mathrm{~Hz}$ to $2 \mathrm{MHz}$.

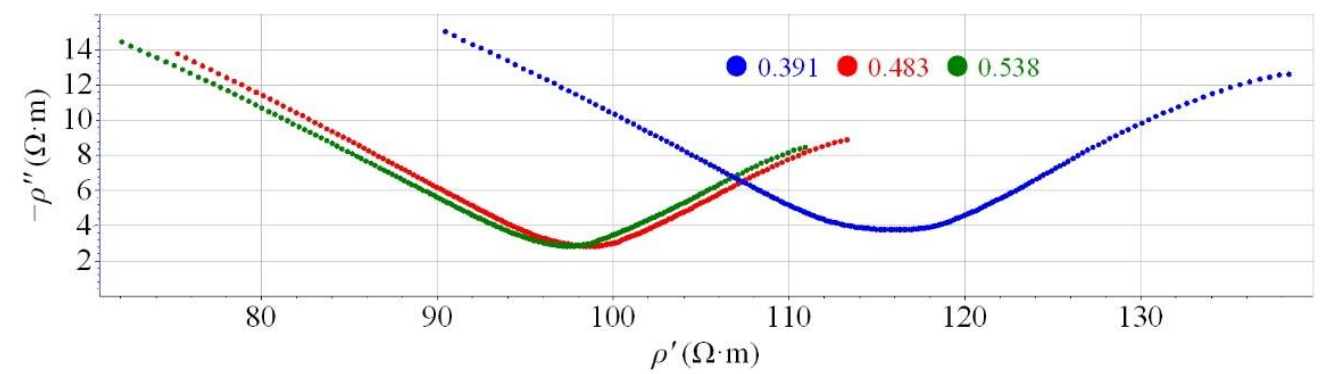

(a)

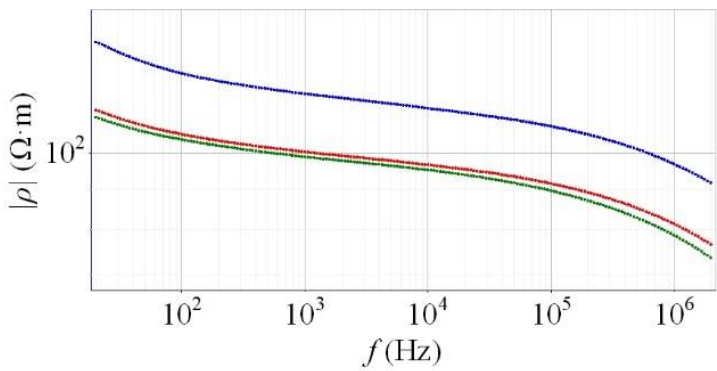

(b)

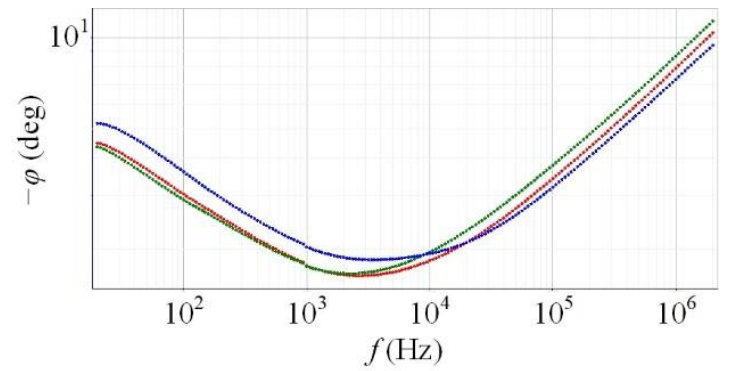

(c)

Figure A3. Cont. 


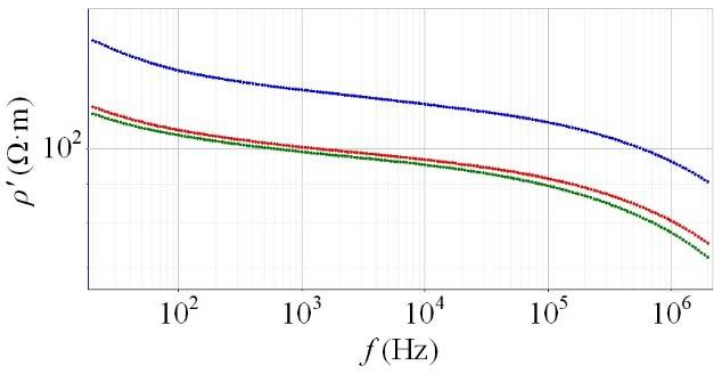

(d)

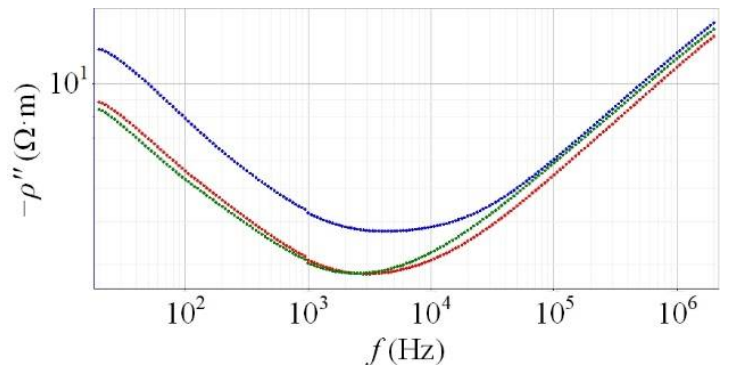

(e)

Figure A3. Impact of changes in dry density on measured complex resistivity of substrate. (a) Nyquist plots; (b) magnitude spectra; (c) phase spectra; (d) in-phase conductivity spectra; (e) quadrature conductivity spectra. For the spectra marked by different colors, the variable dry densities are provided in (a), while the related volumetric water contents (Table 3) are considered to be nearly equal. The frequency range is from $20 \mathrm{~Hz}$ to $2 \mathrm{MHz}$.

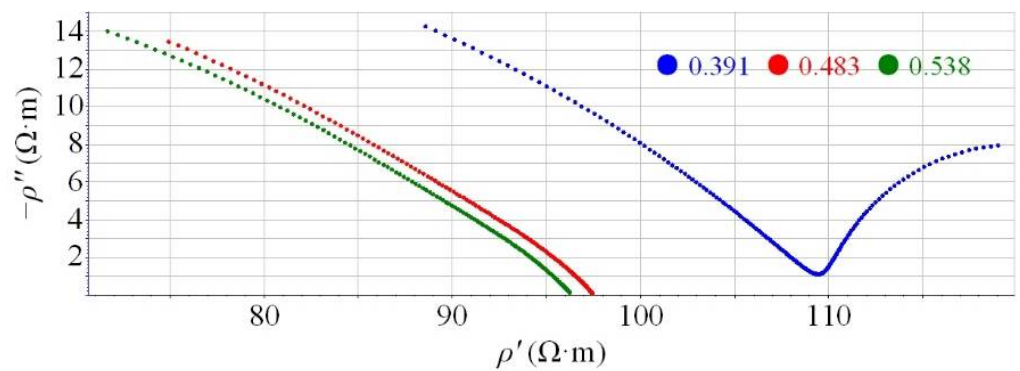

(a)

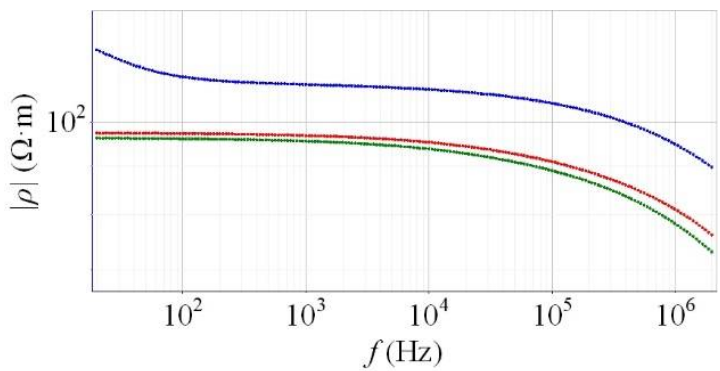

(b)

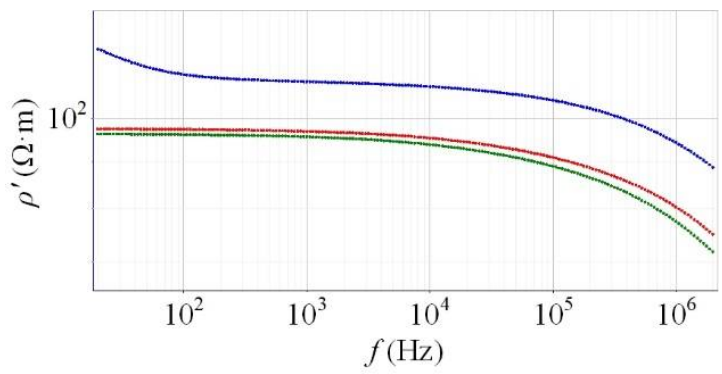

(d)

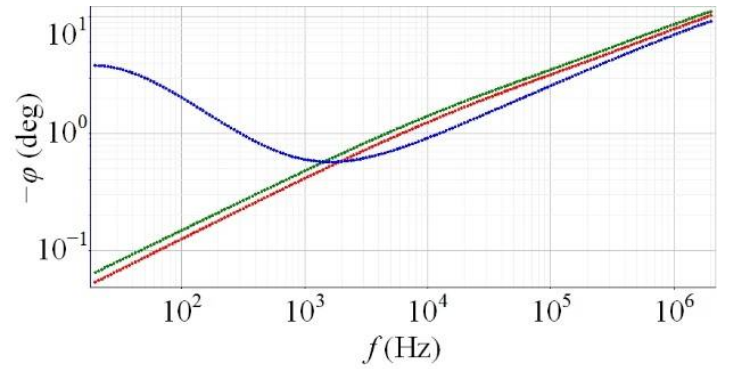

(c)

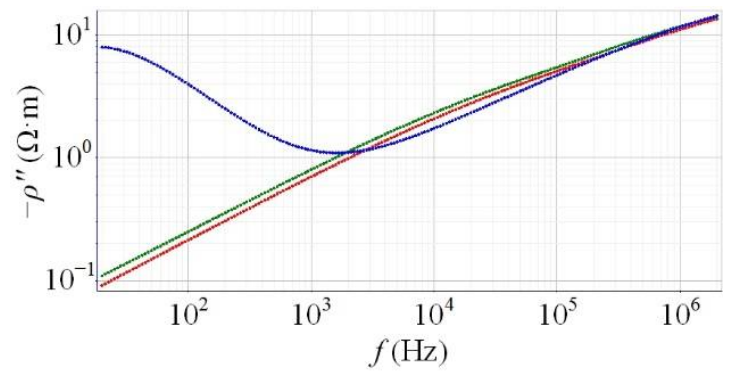

(e)

Figure A4. Impact of changes in dry density on complex resistivity of substrate. (a) Nyquist plots; (b) magnitude spectra; (c) phase spectra; (d) in-phase conductivity spectra; (e) quadrature conductivity spectra. For the spectra marked by different colors, the variable dry densities are provided in (a), while the related volumetric water contents (Table 3) are considered to be nearly equal. The frequency range is from $20 \mathrm{~Hz}$ to $2 \mathrm{MHz}$. 


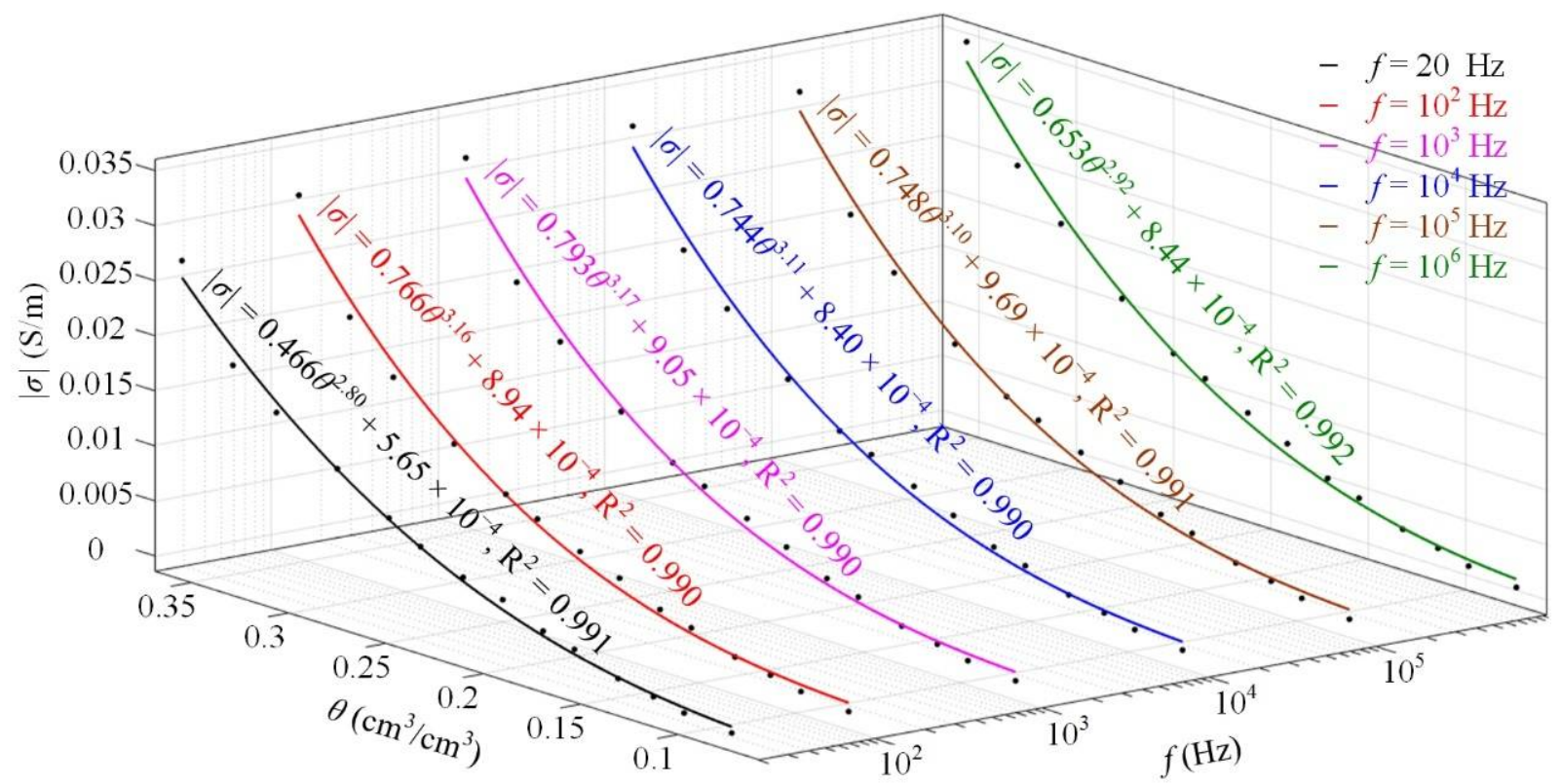

Figure A5. Fitted relations between substrate conductivity magnitude and volumetric water content at different frequencies for a typical set of substrates at nearly equal dry densities. The mean and standard deviation of the related dry densities (Table 1) are of $0.398 \mathrm{~g} / \mathrm{cm}^{3}$ and $4.97 \times 10^{-3}$, respectively.

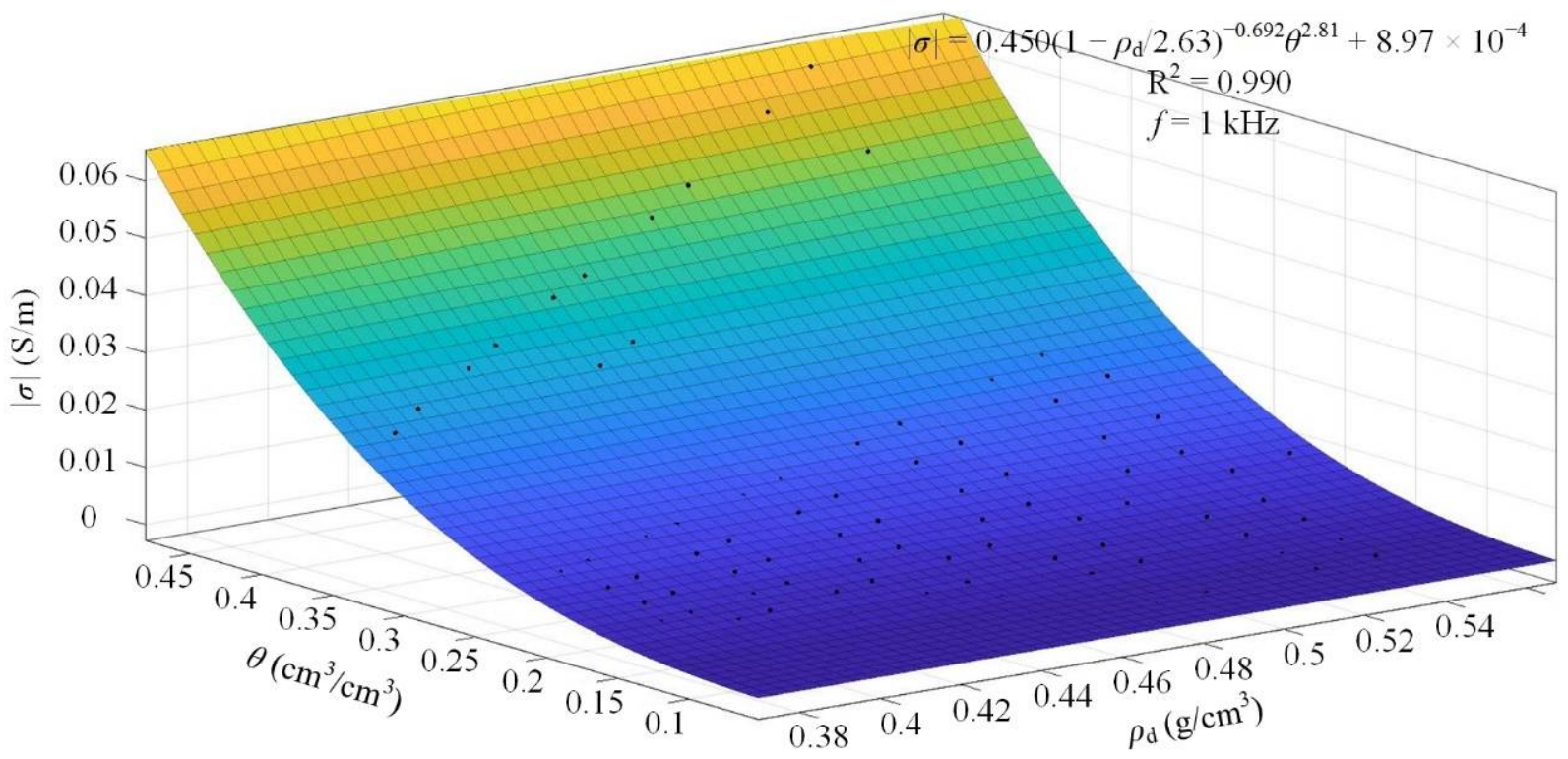

Figure A6. Fitted relation for substrate conductivity magnitude as a function of volumetric water content and dry density at the frequency of $1 \mathrm{kHz}$. The related dry densities and VWCs are shown in Tables S1 and S2, respectively. 


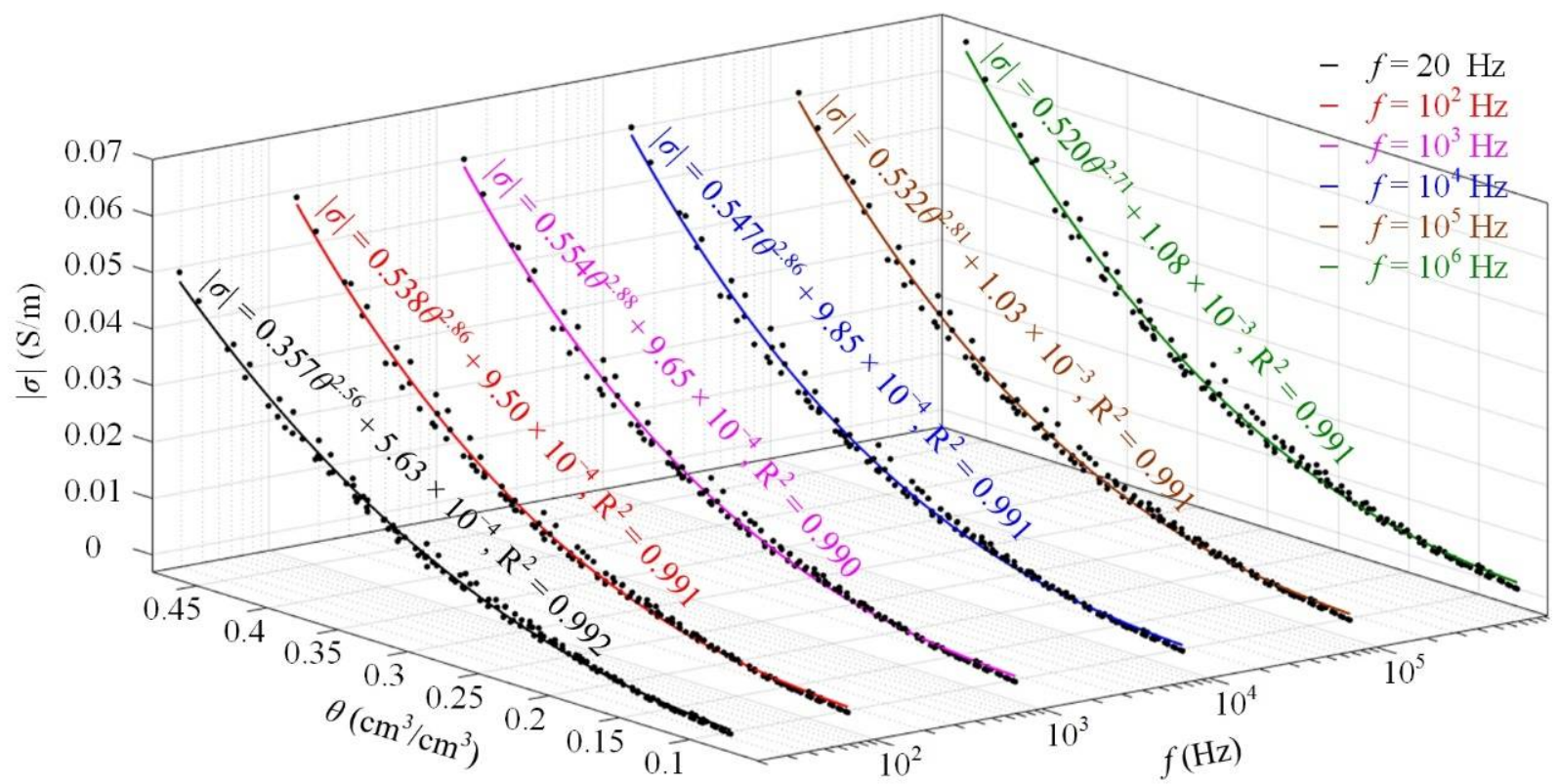

Figure A7. Fitted relations between substrate conductivity magnitude and volumetric water content at different frequencies for the substrates with certain variability in dry density. The mean and standard deviation of the dry densities (Table S1) are $0.455 \mathrm{~g} / \mathrm{cm}^{3}$ and $5.04 \times 10^{-2}$, respectively.

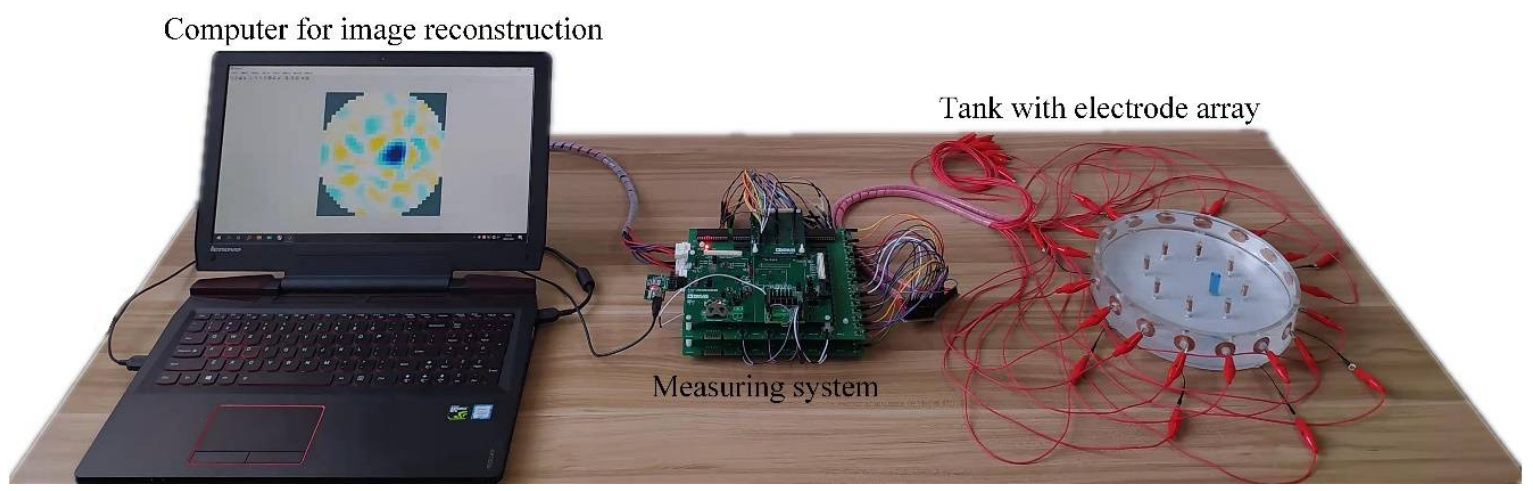

(a)

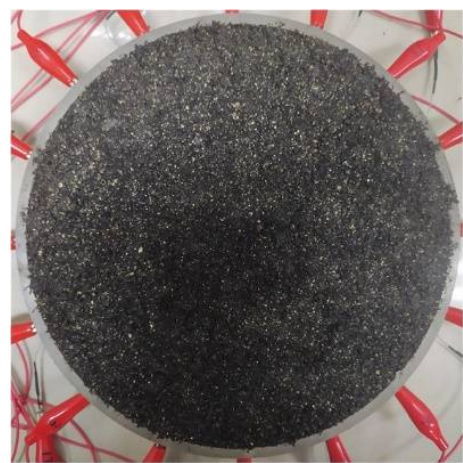

(b)

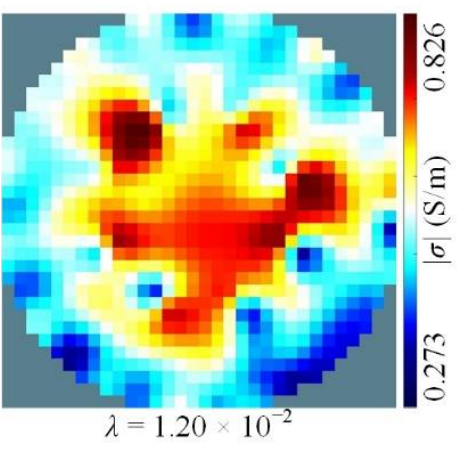

(c)

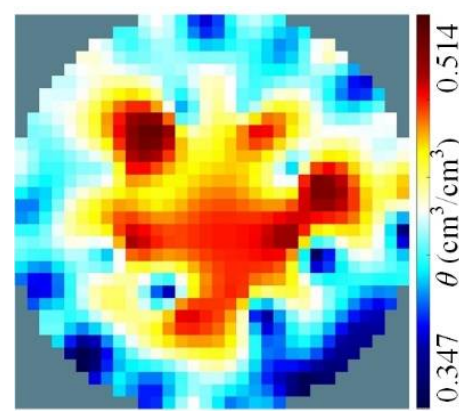

(d)

Figure A8. Exemplary application of a moisture-conductivity relation for mapping of moisture in a substrate zone, using electrical imaging. (a) Photograph of the experimental setup; (b) photograph of the substrate zone; (c) reconstructed image of the conductivity distribution; (d) image of the moisture distribution. 


\section{References}

1. Zhao, P.-F.; Wang, Y.-Q.; Yan, S.-X.; Fan, L.-F.; Wang, Z.-Y.; Zhou, Q.; Yao, J.-P.; Cheng, Q.; Wang, Z.-Y.; Huang, L. Electrical imaging of plant root zone: A review. Comput. Electron. Agric. 2019, 167, 105058. [CrossRef]

2. Cimpoiaşu, M.O.; Kuras, O.; Pridmore, T.; Mooney, S.J. Potential of geoelectrical methods to monitor root zone processes and structure: A review. Geoderma 2020, 365, 114232. [CrossRef]

3. Jayawickreme, D.H.; van Dam, R.L.; Hyndman, D. Subsurface imaging of vegetation, climate, and root-zone moisture interactions. Geophys. Res. Lett. 2008, 35, L18404. [CrossRef]

4. Jayawickreme, D.H.; van Dam, R.L.; Hyndman, D.W. Hydrological consequences of land-cover change: Quantifying the influence of plants on soil moisture with time-lapse electrical resistivity. Geophysics 2010, 75, WA43-WA50. [CrossRef]

5. Moreno, Z.; Arnon-Zur, A.; Furman, A. Hydro-geophysical monitoring of orchard root zone dynamics in semi-arid region. Irrig. Sci. 2015, 33, 303-318. [CrossRef]

6. Cassiani, G.; Kemna, A.; Villa, A.; Zimmermann, E. Spectral induced polarization for the characterization of free-phase hydrocarbon contamination of sediments with low clay content. Near Surf. Geophys. 2009, 7, 547-562. [CrossRef]

7. Cassiani, G.; Boaga, J.; Vanella, D.; Perri, M.T.; Consoli, S. Monitoring and modelling of soil-plant interactions: The joint use of ERT, sap flow and eddy covariance data to characterize the volume of an orange tree root zone. Hydrol. Earth Syst. Sci. 2015, 19, 2213-2225. [CrossRef]

8. Cassiani, G.; Boaga, J.; Rossi, M.; Putti, M.; Fadda, G.; Majone, B.; Bellin, A. Soil-plant interaction monitoring: Small scale example of an apple orchard in Trentino, North-Eastern Italy. Sci. Total Environ. 2016, 543, 851-861. [CrossRef] [PubMed]

9. Furman, A.; Arnon-Zur, A.; Assouline, S. Electrical Resistivity Tomography of the Root Zone. In Soil-Water-Root Processes: Advances in Tomography and Imaging; Anderson, S.H., Hopmans, J.W., Eds.; The Soil Science Society of America, Inc.: Madison, WI, USA, 2013; Volume 615, pp. 223-245. [CrossRef]

10. Brillante, L.; Bois, B.; Mathieu, O.; Bichet, V.; Michot, D.; Lévêque, J. Monitoring soil volume wetness in heterogeneous soils by electrical resistivity. A field-based pedotransfer function. J. Hydrol. 2014, 516, 56-66. [CrossRef]

11. Abdulsamad, F.; Revil, A.; Prime, N.; Gnonnoue, P.Y.; Schmutz, M.; Plé, O. Complex conductivity of rammed earth. Eng. Geol. 2020, 273, 105697. [CrossRef]

12. Breede, K.; Kemna, A.; Esser, O.; Zimmermann, E.; Vereecken, H.; Huisman, J.A. Spectral induced polarization measurements on variably saturated sand-clay mixtures. Near Surf. Geophys. 2012, 10, 479-489. [CrossRef]

13. Revil, A.; Coperey, A.; Shao, Z.; Florsch, N.; Fabricius, I.L.; Deng, Y.; Delsman, J.R.; Pauw, P.S.; Karaoulis, M.; De Louw, P.G.B.; et al. Complex conductivity of soils. Water Resour. Res. 2017, 53, 7121-7147. [CrossRef]

14. Deng, Y.; Shi, X.; Revil, A.; Wu, J.; Ghorbani, A. Complex conductivity of oil-contaminated clayey soils. J. Hydrol. 2018, 561, 930-942. [CrossRef]

15. Gao, Z.; Haegel, F.-H.; Esser, O.; Zimmermann, E.; Vereecken, H.; Huisman, J.A. Spectral Induced Polarization of Biochar in Variably Saturated Soil. Vadose Zone J. 2019, 18, 1-13. [CrossRef]

16. Wang, Y.-Q.; Zhao, P.-F.; Fan, L.-F.; Zhou, Q.; Wang, Z.-Y.; Song, C.; Chai, Z.-Q.; Yue, Y.; Huang, L.; Wang, Z.-Y. Determination of water content and characteristic analysis in substrate root zone by electrical impedance spectroscopy. Comput. Electron. Agric. 2019, 156, 243-253. [CrossRef]

17. Dong, X.Q.; Yang, G.H.; Bai, X.H.; Park, J. The alternating current impedance characteristics of silty soil with various water contents. Fresenius Environ. Bull. 2012, 21, 433-440.

18. Chaudhary, P.; Patel, V.; Rana, V.A.; Gadani, D. Dielectric properties of soil mixed with urea fertilizer over $20 \mathrm{~Hz}$ to $2 \mathrm{MHz}$ frequency range. Indian J. Pure Appl. Phys. 2020, 58, 455-464.

19. Ekwue, E.I.; Bartholomew, J. Electrical conductivity of some soils in Trinidad as affected by density, water and peat content. Biosyst. Eng. 2011, 108, 95-103. [CrossRef]

20. Rashid, Q.A.; Abuel-Naga, H.M.; Leong, E.-C.; Lu, Y.; Abadi, A. Experimental-artificial intelligence approach for characterizing electrical resistivity of partially saturated clay liners. Appl. Clay Sci. 2018, 156, 1-10. [CrossRef]

21. Corona-Lopez, D.D.J.; Sommer, S.; Rolfe, S.A.; Podd, F.; Grieve, B.D. Electrical impedance tomography as a tool for phenotyping plant roots. Plant Methods 2019, 15, 49. [CrossRef]

22. Weigand, M.; Kemna, A. Multi-frequency electrical impedance tomography as a non-invasive tool to characterize and monitor crop root systems. Biogeosciences 2017, 14, 921-939. [CrossRef]

23. Weigand, M.; Kemna, A. Imaging and functional characterization of crop root systems using spectroscopic electrical impedance measurements. Plant Soil 2019, 435, 201-224. [CrossRef]

24. Cseresnyés, I.; Vozáry, E.; Kabos, S.; Rajkai, K. Influence of substrate type and properties on root electrical capacitance. Int. Agrophys. 2020, 34, 95-101. [CrossRef]

25. Binley, A. Tools and Techniques: Electrical Methods. In Treatise on Geophysics, 2nd ed.; Schubert, G., Ed.; Elsevier: Oxford, UK, 2015; Volume 11, pp. 233-259. [CrossRef]

26. Deo, R.N.; Cull, J.P. Spectral Induced Polarization Techniques in Soil Corrosivity Assessments. Geotech. Test. J. 2015, 38, 965-977. [CrossRef]

27. Archie, G.E. The Electrical Resistivity Log as an Aid in Determining Some Reservoir Characteristics. Trans. AIME 1942, 146, 54-62. [CrossRef] 
28. Mualem, Y.; Friedman, S.P. Theoretical Prediction of Electrical Conductivity in Saturated and Unsaturated Soil. Water Resour. Res. 1991, 27, 2771-2777. [CrossRef]

29. Revil, A.; Glover, P.W.J. Nature of surface electrical conductivity in natural sands, sandstones, and clays. Geophys. Res. Lett. 1998, 25, 691-694. [CrossRef]

30. Rhoades, J.D.; Raats, P.A.C.; Prather, R.J. Effects of Liquid-phase Electrical Conductivity, Water Content, and Surface Conductivity on Bulk Soil Electrical Conductivity. Soil Sci. Soc. Am. J. 1976, 40, 651-655. [CrossRef]

31. Waxman, M.H.; Smits, L.J.M. Electrical Conductivities in Oil-Bearing Shaly Sands. Soc. Pet. Eng. J. 1968, 8, 107-122. [CrossRef]

32. Robinson, J.L.; Slater, L.D.; Schäfer, K.V.R. Evidence for spatial variability in hydraulic redistribution within an oak-pine forest from resistivity imaging. J. Hydrol. 2012, 430, 69-79. [CrossRef]

33. Li, X.J.; Wang, X.; Zhao, Q.; Zhang, Y.Y.; Zhou, Q.X. In Situ Representation of Soil/Sediment Conductivity Using Electrochemical Impedance Spectroscopy. Sensors 2016, 16, 625. [CrossRef] [PubMed]

34. Vanderborght, J.; Huisman, J.; Kruk, J.; Vereecken, H. Geophysical Methods for Field-Scale Imaging of Root Zone Properties and Processes. In Soil-Water-Root Processes: Advances in Tomography and Imaging; Anderson, S.H., Hossaspmans, J.W., Eds.; The Soil Science Society of America, Inc.: Madison, WI, USA, 2013; Volume 61, pp. 247-282. [CrossRef]

35. Beff, L.; Günther, T.; Vandoorne, B.; Couvreur, V.; Javaux, M. Three-dimensional monitoring of soil water content in a maize field using Electrical Resistivity Tomography. Hydrol. Earth Syst. Sci. 2013, 17, 595-609. [CrossRef]

36. Chen, B.Q.; Garré, S.; Liu, H.T.; Yan, C.R.; Liu, E.K.; Gong, D.Z.; Mei, X.R. Two-dimensional monitoring of soil water content in fields with plastic mulching using electrical resistivity tomography. Comput. Electron. Agric. 2019, 159, 84-91. [CrossRef]

37. Garré, S.; Javaux, M.; Vanderborght, J.; Pagès, L.; Vereecken, H. Three-Dimensional Electrical Resistivity Tomography to Monitor Root Zone Water Dynamics. Vadose Zone J. 2011, 10, 412-424. [CrossRef]

38. Hussain, K.; Wongleecharoen, C.; Hilger, T.; Vander Borght, J.; Garré, S.; Onsamrarn, W.; Sparke, M.-A.; Diels, J.; Kongkaew, T.; Cadisch, G. Combining $\delta 13 \mathrm{C}$ measurements and ERT imaging: Improving our understanding of competition at the crop-soilhedge interface. Plant Soil 2015, 393, 1-20. [CrossRef]

39. Rao, B.H.; Bhat, A.M.; Singh, D.N. Application of impedance spectroscopy for modeling flow of AC in soils. Géoméch. Geoengin. Int. J. 2007, 2, 197-206. [CrossRef]

40. ASTM. ASD18 CommitM D854-14, Standard Test Methods for Specific Gravity of Soil Solids by Water Pycnometer; ASTM International: West Conshohocken, PA, USA, 2014. [CrossRef]

41. Adler, A.; Lionheart, W.R.B. Uses and abuses of EIDORS: An extensible software base for EIT. Physiol. Meas. 2006, 27, S25-S42. [CrossRef]

42. Volkmann, J.; Klitzsch, N. Wideband impedance spectroscopy from $1 \mathrm{mHz}$ to $10 \mathrm{MHz}$ by combination of four- and two-electrode methods. J. Appl. Geophys. 2015, 114, 191-201. [CrossRef]

43. Kemna, A.; Binley, A.; Cassiani, G.; Niederleithinger, E.; Revil, A.; Slater, L.; Williams, K.H.; Orozco, A.F.; Haegel, F.-H.; Hördt, A.; et al. An overview of the spectral induced polarization method for near-surface applications. Near Surf. Geophys. 2012, 10, 453-468. [CrossRef]

44. Garré, S.; Günther, T.; Diels, J.; VanderBorght, J. Evaluating Experimental Design of ERT for Soil Moisture Monitoring in Contour Hedgerow Intercropping Systems. Vadose Zone J. 2012, 11, vzj2011.0186. [CrossRef]

45. Garré, S.; Coteur, I.; Wongleecharoen, C.; Kongkaew, T.; Diels, J.; VanderBorght, J. Noninvasive Monitoring of Soil Water Dynamics in Mixed Cropping Systems: A Case Study in Ratchaburi Province, Thailand. Vadose Zone J. 2013, 12, 1-12. [CrossRef] 